\title{
Modeling the impacts of future climate change on water resources for the Gállego river basin (Spain)
}

\author{
B. Majone, ${ }^{1}$ C. I. Bovolo, ${ }^{2}$ A. Bellin, ${ }^{1}$ S. Blenkinsop, ${ }^{2}$ and H. J. Fowler ${ }^{2}$ \\ Received 1 June 2011; revised 11 November 2011; accepted 22 November 2011; published 14 January 2012.
}

[1] Global changes in climate may have large impacts on regional water resources and the frequency of drought or flood events. Changes in precipitation or temperature may also severely modify the available water resources for users in several sectors. Here, we examine climate change scenarios for the Gállego river (a tributary of the larger Ebro river in Spain) in the context of quantitative water resources management for the basin. Projected changes to precipitation and temperature are derived from an ensemble of 6 Regional Climate Models (RCMs) run for the period 2071-2100 under the SRES A2 emissions scenario and are subsequently bias corrected before input into a hydrological model. The use of RCM ensembles is important for the incorporation of uncertainties derived from different model structures, parameterizations and boundary conditions into the hydrological modeling process and subsequent climate change impact assessment. All 6 RCMs project decreases in annual precipitation with some RCMs projecting a slight increase between December and February. Additionally, all models project a $>3^{\circ} \mathrm{C}$ increase in annual mean temperature over the basin, with some models projecting a $9^{\circ} \mathrm{C}$ temperature increase during summer months. Hydrological simulations using the GEOTRANSF model, with the climate change scenarios as input, show that projected water availability for the Gállego is lower for the 2071-2100 period than for 1961-1990, with an increasing number of dry years. During the water-storage period (October to March), medium to low flows are reduced, while during the irrigation period (April to September), streamflow is reduced across the entire range of flows. The projected changes vary across the basin and are also not uniform throughout the year. Stronger drying occurs during the summer with potentially important implications for water resource management across many sectors including agriculture, with a reduction in the amount of water available for irrigation and hydropower generation, due to projected seasonal reductions in reservoir levels.

Citation: Majone, B., C. I. Bovolo, A. Bellin, S. Blenkinsop, and H. J. Fowler (2012), Modeling the impacts of future climate change on water resources for the Gállego river basin (Spain), Water Resour. Res., 48, W01512, doi:10.1029/2011WR010985.

\section{Introduction}

[2] Climate change is projected to have a significant impact on streamflow with an adverse impact on water resources availability and operation of existing hydraulics infrastructures [Kundzewicz et al., 2007], which represents a potential threat to the security of water resources. This is particularly the case across the Iberian Peninsula where climate projections indicate a risk of increasingly arid conditions. These could result in increased water stress on both agricultural and natural ecosystems [Gao and Giorgi, 2008] and are indicative of changes across the Mediterranean region [Beniston et al., 2007, de Castro et al., 2007]. As a consequence of these changes it is also expected that by the 2070 s hydropower potential will decrease by $20-50 \%$

\footnotetext{
${ }^{1}$ Department of Civil and Environmental Engineering, University of Trento, Trento, Italy.

${ }^{2}$ Water Resource Systems Research Laboratory, School of Civil Engineering and Geosciences, University of Newcastle upon Tyne, Newcastle upon Tyne, UK.
}

Copyright 2012 by the American Geophysical Union 0043-1397/12/2011WR010985 around the Mediterranean [Alcamo et al., 2007]. Changes in climate therefore pose problems for the operation of water resource systems which have historically been designed under the assumption of stationarity [Milly et al., 2008].

[3] Historical observations indicate recent warming over the Iberian Peninsula [Brunet et al., 2007; Martínez et al., 2010] while dry conditions have also become more likely over the last 50 years [Rodrigo, 2010]. This has been accompanied by a general tendency toward a decrease in the average intensity of precipitation [Goodess and Jones, 2002; Rodrigo and Trigo, 2007], although monthly trends show considerable spatial and temporal variability [GonzalezHidalgo et al., 2009]. Over the northeast Iberian Peninsula, which includes the Ebro basin, precipitation has generally decreased over this period, particularly during winter and spring [López-Moreno et al., 2010a]. Although changes in precipitation have been associated with a decrease in runoff across the Ebro basin [López-Moreno et al., 2010b], there are likely to be multiple drivers of this change [Cudennec et al., 2007; López-Moreno et al., 2008b], the high level of anthropogenic influences making this basin difficult to model. As a consequence of decreasing river discharges over recent decades and natural variability of precipitation during the storage 
season, changes to the management of reservoirs have been required to maintain storage volumes for the irrigation season [López-Moreno et al., 2004]. Assessments of the long-term sustainability of water resources use and exploitation should take into account the impact of changes in precipitation and air temperature on streamflow, since a large part of the water resources used in agriculture and in the energy production compartment are surface water resources.

[4] General Circulation Models (GCMs), used to simulate climate on a global scale, typically have a horizontal resolution of $\sim 300 \mathrm{~km}$ and are therefore inadequate to represent hydrological processes at scales smaller than the continental scale. Dynamical downscaling through the use of higherresolution regional climate models $(\mathrm{RCMs})$ (typically $\sim 25$ $50 \mathrm{~km}$ ) may still not provide the resolution required for robust hydrological modeling. A recent study showed that the long-term average of the mean annual streamflow of 165 large river basins with drainage area larger than $50,000 \mathrm{~km}^{2}$, estimated by subtracting the evapotranspiration from the precipitation, both evaluated through RCMs, had relative deviations from the observations that in some cases were of the order of $100 \%$ [Milly et al., 2005]. This is not acceptable if the objective of the simulations is to perform reliable projections of water resources availability, particularly in heavily exploited catchments. Even worse, in catchments with a drainage area of a few thousand $\mathrm{km}^{2}$ the deviations are expected to be larger, thus invalidating projections. To partially alleviate this problem, a wide range of statistical approaches may be applied to downscale further to the resolution of observed climate data. These approaches are reviewed in detail by Wilby and Wigley [1997] and with a focus on hydrological applications by Fowler et al. [2007]. One of the remaining challenges however is to represent uncertainty in future projections of climate and the impacts associated with any change. Although a robust strategy to assess future impacts on hydrological systems requires an end-to-end consideration of the uncertainty cascade [Wilby and Dessai, 2010], uncertainty derived from climate modeling has been demonstrated in some areas to be greater than that arising from hydrological modeling [e.g., Kay et al., 2009]. Climate model uncertainty is increasingly being addressed through the use of multimodel ensembles (e.g., PRUDENCE [Christensen et al., 2007b], ENSEMBLES [Hewitt and Griggs, 2004, van der Linden and Mitchell, 2009]) and perturbed physics ensembles [Tebaldi and Knutti, 2007; Collins, 2007; Murphy et al., 2007] and their application in impacts studies [e.g., Blenkinsop and Fowler, 2007; New et al., 2007; Fowler et al., 2007].

[5] Climate model ensembles suggest future decreases in precipitation over southern Europe [Christensen et al., 2007 a], indicating that annual precipitation is very likely to decrease in the Mediterranean area while the risk of summer drought is likely to increase. The PRUDENCE RCM ensemble [Bürger et al., 2007], also used in this study, indicates a decrease in mean precipitation over the Iberian Peninsula by 2100 , although there is uncertainty in the magnitude of projected change on the regional scale. Most climate models also project the Iberian Peninsula to experience the greatest summer warming [Christensen and Christensen, 2007; Christensen et al., 2007a] which may drive a decrease in snow accumulation over the Pyrenees [López-Moreno et al., 2008b, 2009]. PRUDENCE RCMs also project lower precipitation and warmer temperatures to the southern side of the Pyrenees, which will affect the hydrology of the Ebro basin and place stress on water resources derived from seasonal glaciers and snowmelt [López-Moreno et al., 2008a]. Overall climatic changes projected for this region suggest a reduced future capacity for runoff generation [López-Moreno et al., 2010b].

[6] To date, few studies have addressed water resources management under uncertain future climate conditions. Most of the existing studies examine the likely impacts of climate change on current operating policies based on single climate projections. For example, Yao and Georgakakos [2001] presented an integrated forecast decision methodology to assess reservoir performance under historical and future scenario based on projections derived from one GCM. Tanaka et al. [2006] examined the capability of California's water supply system to cope with the likely impacts of climate change using an economic-engineering optimization model and only two climate scenarios. However, the more recent works of Vicuna et al. [2010] and Deepashree and Mujumdar [2010] assessed the effects of climate change on multipurpose reservoirs in the Merced (USA) and Mahanadi (India) river basins, respectively, by considering an adaptive management strategy using climate change scenarios from eleven and three GCMs, respectively.

[7] Most climate models project an increase in aridity of the Mediterranean regions with a potential impact on the future availability of water resources. In this context the Gàllego is an interesting study area due to the combination of the large projected changes in regional climate and the fact that water resources are already under pressure due to intensive agriculture [Bovolo et al., 2011]. In the present work we analyze the projected impacts of climate change on water resources availability in the Gállego river basin by coupling output from an ensemble of RCM experiments with a parsimonious hydrological model. In a more general sense, we study how uncertainty in climate modeling propagates through the hydrological modeling to affect projections of future water resources availability and management. Furthermore, with this approach we obtain a more complete treatment of uncertainty with respect to existing studies in the Iberian Peninsula which typically deal with a much smaller number of climatic scenarios [e.g., Kilsby et al., 2007]. This work also provides the most robust estimates of future change to date for water resources in this region.

[8] The paper is organized as follows: section 2 presents a description of the study area followed, in section 3 , by a description of the hydrological model including model setup, calibration and validation procedure. Climate-forcing data are then presented in section 4 , followed in section 5 by the validation of the hydrological model for the period 1961-1990. The main results on the possible effects of climate change on the hydrological system and water resources of the catchment are presented in section 6, and finally we draw some conclusions in section 7 .

\section{Study Area}

[9] The Gállego River rises in the central Pyrenees and runs from north to south to meet the Ebro River at Zaragoza with a total contributing area of $4009 \mathrm{~km}^{2}$ (see Figure 1). The northern part of the Gállego catchment is composed of 


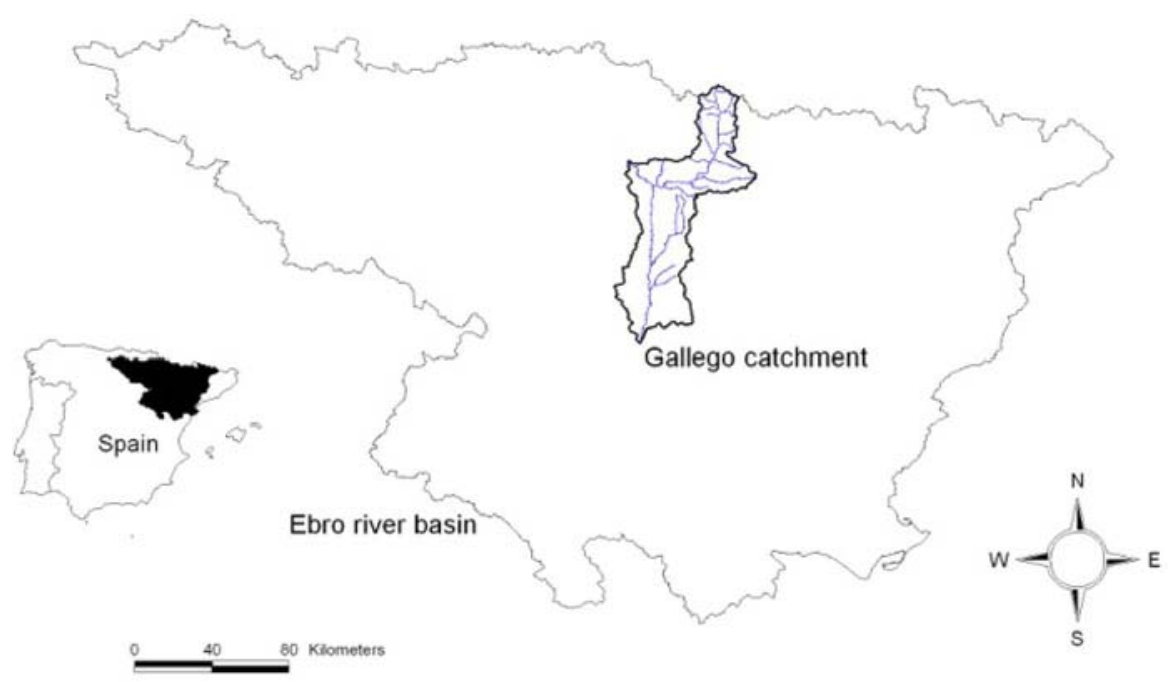

Figure 1. Map showing the location of the Gállego catchment within the Ebro river basin. The inset shows the location of the Ebro river basin in the Iberian Peninsula.

rock formations generated by the Alpine orogenesis that formed the Pyrenees, while the southern part is composed mainly of Miocene sediments. Overall, the basin has an average slope of $1 \%$, which decreases to $0.4 \%$ in proximity of the conjunction with the Ebro.

[10] The Ebro basin authority, the "Confederacion Hidrografica del Ebro" (CHE), estimates that under a natural regime the average annual streamflow of the Gállego at its conjunction with the Ebro would be $34.4 \mathrm{~m}^{3} \mathrm{~s}^{-1}$ (CHE, Plan Hidrologico del Rio Gállego, 2007, available at http:// www.chebro.es). However, its natural regime is altered by reservoirs and channels which serve several hydropower and irrigation systems. Climate in the Gállego catchment ranges from cold and wet in the northern regions, with a mean annual temperature of $4^{\circ} \mathrm{C}$ and mean annual precipitation of $1330 \mathrm{~mm} \mathrm{yr}^{-1}$, to semiarid in the southern regions, where the mean annual temperature rises to $14^{\circ} \mathrm{C}$ and mean annual precipitation declines to $370 \mathrm{~mm} \mathrm{yr}^{-1}$ (CHE, online report, 2007). Average monthly precipitation and temperature for the period 1961-90 for the Gállego catchment (including the upper and lower parts of the basin) for all gauges used in the study are shown in Figure 2. Potential evapotranspiration (PET) ranges from $500 \mathrm{~mm} \mathrm{yr}^{-1}$ in the northern regions to $800 \mathrm{~mm} \mathrm{yr}^{-1}$ in the southern regions. Given this disparity in available water resources, a dense network of hydraulic infrastructure has been built since the 1960s in order to sustain agricultural activities in the south of the catchment.

[11] In addition, a significant amount of water stored in the reservoirs in autumn and winter (between October and March) are transferred to the Cinca basin, a large agricultural area to the east of the Gállego catchment, for irrigation purposes. Reservoirs are operated according to protocols in order to satisfy the water demand of downstream territories for domestic, industrial and hydropower uses, and to maintain the ecological functionality of the river. Flood risk is managed by allocating extra storage capacity to the reservoirs. In summer, between April and September, irrigation demands are high and priority is usually given to satisfying agricultural demand rather than to hydropower production.
[12] The hydrological regime of the Gállego is heavily impacted by several reservoirs and diversion channels built in order to satisfy agricultural needs and provides water to three main irrigated agricultural districts: the Upper Gállego $\left(15.1 \mathrm{~km}^{2}\right)$, the Bajo Gállego $\left(117.2 \mathrm{~km}^{2}\right)$ and La Violada $\left(90.0 \mathrm{~km}^{2}\right)$. Furthermore, the Monegros district, which is located within the Cinca catchment, is also partially supplied by the Gállego through the Monegros channel. Under the supervision of CHE, irrigation agencies distribute water according to specified rights and demands.

\section{Hydrological Model}

[13] The hydrological model adopted in this study is GEOTRANSF, a semidistributed modeling system which includes hydraulic infrastructures such as reservoirs and

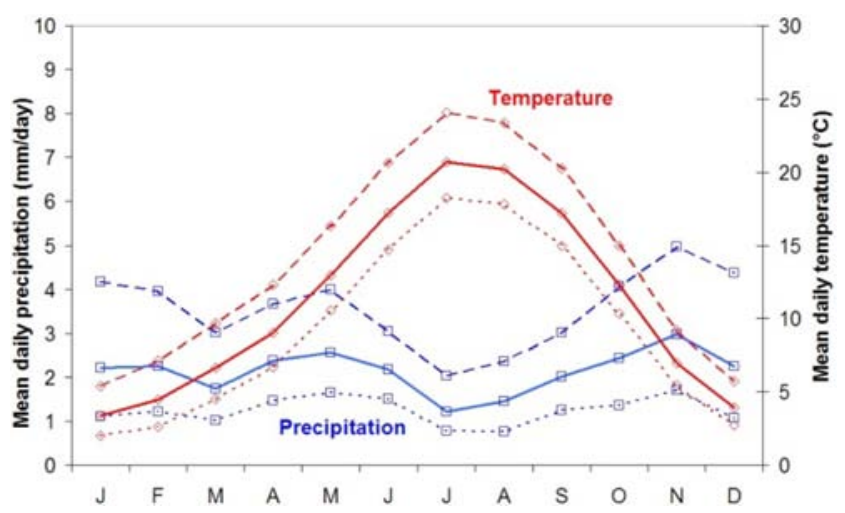

Figure 2. Mean monthly observed precipitation (squares) and temperature (diamonds) for 1961-1990 for the Gállego catchment based on all available datasets used within the study. The means for the whole catchment are shown as a solid line while means for the upper and lower portions of the catchment are shown as dashed and dotted lines, respectively. 
diversion channels (B. Majone, A. Bertagnoli, and A. Bellin, Structure of the modeling system with detailed description of the models. AquaTerra Deliverable C3.2, 2005, available at http://www.eu-aquaterra.de/51.0.ht). GEOTRANSF is built around a conceptual model that limits the model's complexity while maintaining an accurate description of the main mechanisms controlling runoff production at the basin scale.

[14] The modeling system is modular and implements suitable modules for snow accumulation and melting, infiltration, evapotranspiration, subsurface flow generation and channel routing. Its structure is shown in Figure 3. GEOTRANSF identifies two types of core geomorphological units; a subcatchment and a channel. The former is a small portion of the catchment where hillslope processes dominate and the latter is the base element composing the river network that connects the subcatchments to the control section. Mass balance is applied to each subcatchment under the assumption that streamflow at its outlet depends nonlinearly upon water storage [Kirchner, 2009; Majone et al., 2010]. In the most refined implementation of this conceptual framework the subcatchment coincides with a hillslope, but it may also be composed of a portion of the catchment including several hillslopes and channels in "upscaled" modeling approaches. Subsequently, streamflow generated in each subcatchment is routed to the control section by a transfer function which mimics both the retardation and storage effects of the channel network [Rinaldo et al., 2005]. The modular structure of GEOTRANSF facilitates the inclusion of elements such as reservoirs and diversion channels into the modeling system, a feature which is very useful in the present study and in all situations in which

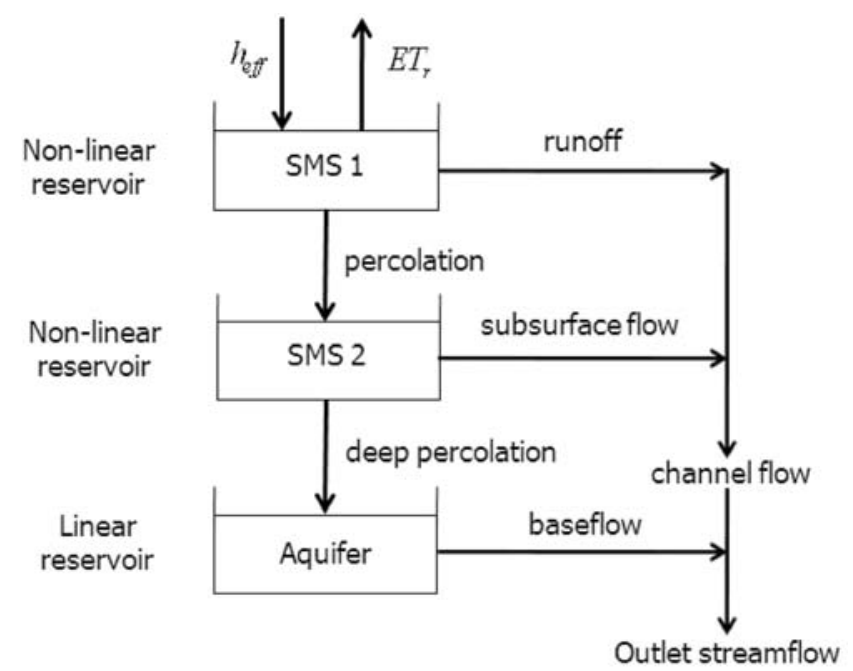

[channel flow is routed to the outlet using GIUH routing]

[baseflow is transferred to the outlet using a linear transfer function]

Legend

$\mathrm{ET}_{\mathrm{r}}=$ Real evapotranspiration

$\mathrm{h}_{\text {eff }}=$ Effective precipitation induding snowmelt and snow accumulation

SMS = Soil Moisture Store

Figure 3. Structure of the semidistributed hydrological model GEOTRANSF. natural streamflow is altered by withdrawals and reservoirs. For example, the effect of a reservoir is simulated by solving the mass balance equation at the reservoir level with the water discharge entering the reservoir provided by the hydrological model and the output water discharge assigned according to the regulation rules. In doing this we implicitly assume that evaporation losses from the reservoir's surface are balanced by direct precipitation. Furthermore, a functional relationship between stored water volume and level of the reservoir is established for each of the modeled reservoirs.

[15] Using this modeling framework, the catchment is first divided into subcatchments (hillslopes), each of them draining into a channel of the river network (see Figure 4a). At a higher hierarchy level, several subcatchments are aggregated into macroareas. Each macroarea is identified as the portion of the whole catchment contributing to a node of the network corresponding to a stream gauge, a reservoir, a point of connection between the river and a diversion channel, or a section where streamflow is computed. The hydrological response of the macroarea is then computed by coupling flow generation at the subcatchment, where nonlinear hillslope scale processes dominate, to a Geomorphological Instantaneous Unit Hydrograph (GIUH) model describing the influence of the river network on streamflow [see e.g., Rodríguez-Iturbe and Valdes, 1979; Rodríguez-Iturbe and Rinaldo, 1997]. The response of the subcatchment is modeled by using a nonlinear bucket model in which the water discharge, $q(t)\left[\mathrm{L}^{3} \mathrm{~T}^{-1}\right]$, depends upon the specific volume stored within the subcatchment through the following expression: $q(t)=\left(1-C_{q}\right) q_{0} \exp \left[\left(h(t)-h_{0}\right) / m\right]$, where $h(t)[\mathrm{L}]$ is the amount of water stored at time $t, q_{0}\left[\mathrm{~L}^{3} \mathrm{~T}^{-1}\right]$ is the water discharge at the initial time when the storage is $h_{0}, m$ is a suitable fitting parameter which depends on the geological, vegetational and pedological characteristics of the catchment and is considered constant within the macroarea, and $c_{q}$ is a partition coefficient introduced in order to accommodate for water not contributing to streamflow because of deep infiltration into the underlying rock formation. At each time step, $h(t)$ is computed using a mass balance equation which takes into account snow accumulation and melt, evapotranspiration and rainfall excess through the SCS-CN method [Michel et al., 2005]. Calibration of the model is performed at nodes where streamflow is measured. A detailed description of the model can be found in the work of Majone et al. [2010, online report, 2005].

\subsection{Model Setup}

[16] It is customary in studies concerning climate change to evaluate the projected changes with respect to a climate model baseline or control (CTRL) period (typically 19611990). Unfortunately, the hydrological model cannot be calibrated on this period for the Gállego river basin since streamflow data are scarce and, importantly, no data is available to reconstruct how basin reservoirs have been managed. Inspection of the entire database showed the period 2000-2005 as the most suitable for calibration. This period has an almost uninterrupted daily streamflow measured at 6 stream gauges and has detailed information regarding reservoir management data and water demands from the irrigation districts. Simulations are therefore conducted using a daily time step for the period 2000-2005. 
However in order to minimize the effects of the initial conditions on the inference of the model's parameters, the year 2000 is simulated but not included into the objective function. Daily precipitation and temperature at 32 rain gauges and 26 temperature stations within the catchment were available from CHE (online, 2007) for the same period. At 18 stations, both precipitation and temperature were recorded while only one parameter was measured at the remaining 14 precipitation and 8 temperature stations. Daily precipitation totals were distributed spatially by using the Ordinary Kriging method, performed by using the 8 nearest stations to the interpolation point, which in our scheme corresponds to the center of mass of each subcatchment. Temperature was computed for each subcatchment by linear interpolation with elevation. The interpolation was performed by using the 6 closest temperature stations and the subcatchment was assigned the temperature corresponding to its mean elevation.

[17] The daily potential evapotranspiration, $E T_{p}\left[\mathrm{~L} \mathrm{~T}^{-1}\right]$, was computed by multiplying the reference daily potential evapotranspiration, $E T_{0}\left[\mathrm{~L} \mathrm{~T}^{-1}\right]$, with a crop coefficient $K_{c}$ which accounts for land use: $E T_{p}=K_{c} \times E T_{0}$ [Allen et al., 1998]. $E T_{0}$ was provided by the Hargreaves and Samani [1982] method which depends only on the mean, maximum and minimum daily temperatures of the subcatchments.

[18] Land use and lithology information (CHE, online, 2007) was used to define both infiltration and crop parameters. The 31 land use categories were grouped into the following 7 major categories: dryland farming, irrigation areas, pastureland, forest, rocks, water and urban areas (see Figure 4b), and the original 44 lithology categories were grouped into four major categories according to infiltration capacity (see Figure 4c), as in the SCS-CN method for separating surface runoff from infiltration developed by the U.S. Soil Conservation Service [U.S. Soil Conservation Service, 1964; Chow et al., 1988]. In the present study we used the modified version of the original SCS-CN method proposed by Michel et al. [2005] which extends the applicability of the methodology to continuous models with periods without precipitation between successive events. We decided to assign each subcatchment a value of Curve Number $(\mathrm{CN})$ which corresponds to the weighted average of the $\mathrm{CN}$ values resulting from coupling the land use map with the lithology map of the catchment. Similarly, we assigned each subcatchment a value of the crop coefficient, $K_{c}$, obtained by a weighted average of the $K_{c}$ values corresponding to the aggregate land use map shown in Figure 4b.

[19] Within the Gállego catchment there are six major reservoirs, all used to provide water for irrigation and hydropower production. The management of these reservoirs depends on specific protocols regulating multiple (and often conflicting) uses. Furthermore, thirteen nonmonitored smaller reservoirs mainly used for hydropower production are located in the northern part of the catchment (Pyrenees). Although no specific information is available on how these reservoirs are operated, the fact that they are used for hydropower production, in conjunction with their small size, suggests that they are operated at a daily time scale with a small to negligible impact on daily streamflow. In the present work we consider only the four reservoirs with the highest storage capacity: Ardisa $\left(5 \times 10^{6} \mathrm{~m}^{3}\right)$, Bubal $\left(57 \times 10^{6} \mathrm{~m}^{3}\right)$, Lanuza $\left(16.8 \times 10^{6} \mathrm{~m}^{3}\right)$ and La Sotonera $\left(179 \times 10^{6} \mathrm{~m}^{3}\right)$ (see Figure 5$)$. As no specific management information was available for the two remaining reservoirs during the calibration period and due to their small storage capacity, these reservoirs were not considered. Each reservoir has its own protocol regulating its use, including priority rules and limitations for flood protection. A further major element influencing streamflow in the Gállego River is the Canal de Gállego (see Figure 5). This channel transfers water from Ardisa to La Sotonera to be used for irrigation.

[20] Two irrigation districts are considered in the model: La Violada and Bajo Gállego (see the striped areas in Figure 5); while the third district, the Upper Gállego, was neglected because no detailed information was available. Notice that this approximation has limited influence on the
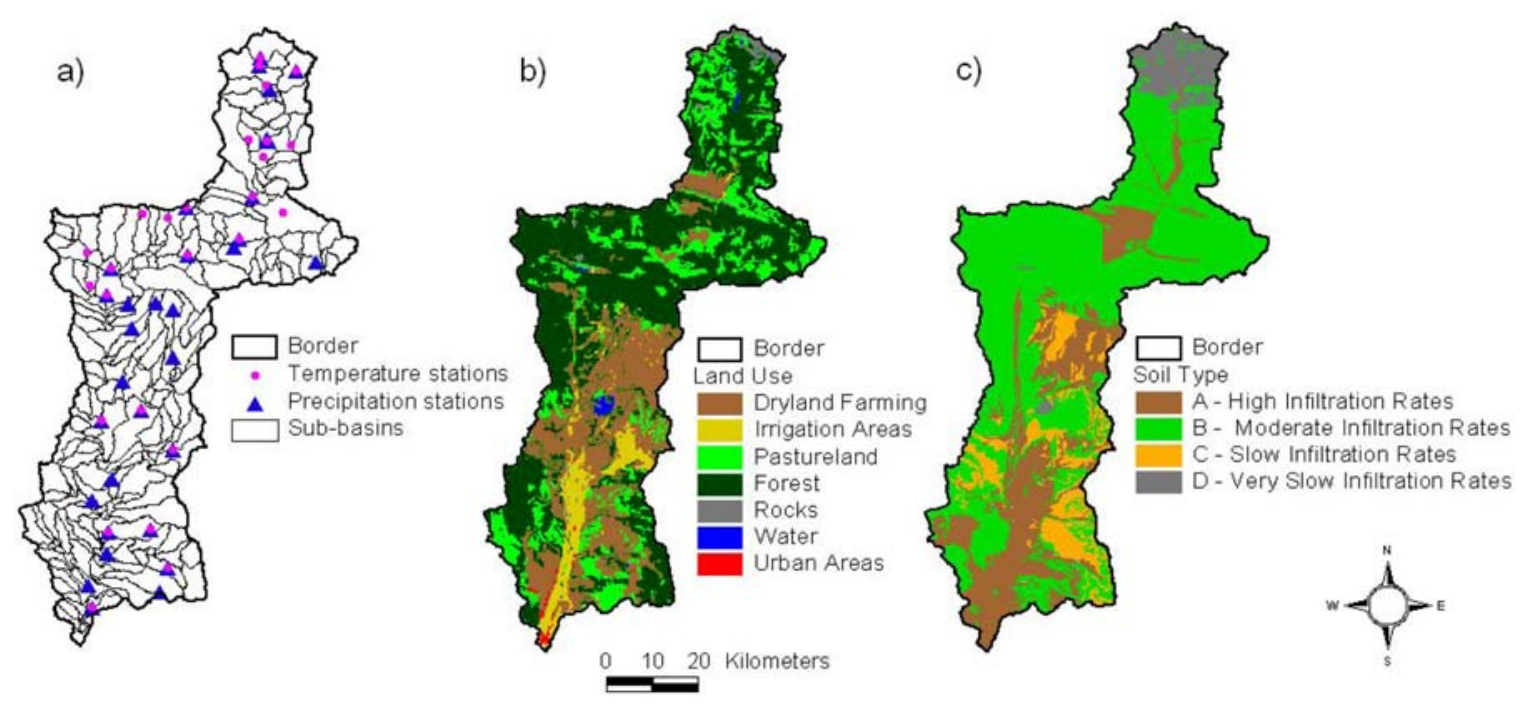

Figure 4. Map showing: (a) the location of the meteorological stations and the subbasins, (b) the land use and (c) the soil type classification in the Gállego river basin. 


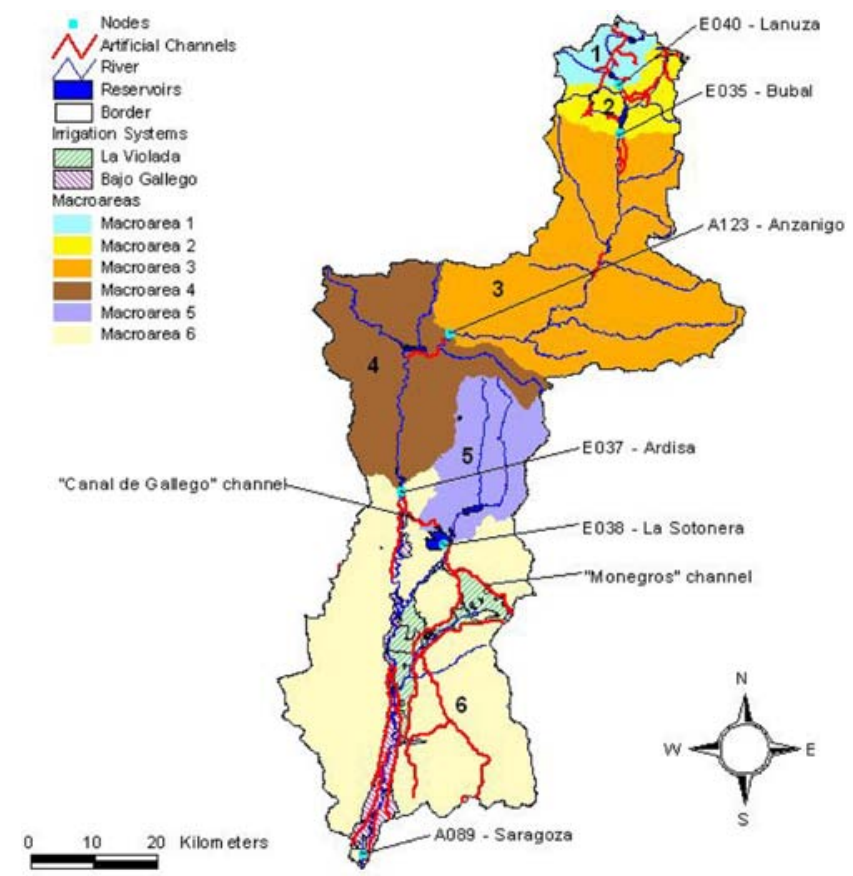

Figure 5. The conceptual model of the Gállego catchment. The subdivision consists of 6 different macroareas, each one characterized by the presence of a node. A indicates an "Aforo" (stream gauge station) while E indicates an "Embalses" (reservoir). The striped areas show the location of the two irrigation districts considered in the study: Bajo Gállego and La Violada. The red lines show the location of the artificial channel network present within the river basin, including the Canal de Gállego and Monegros channels.

model's simulations due to the small area of the Upper Gállego district. The water demand from the Bajo Gállego irrigation system during the 2000-2005 period was about $74.7 \times 10^{6} \mathrm{~m}^{3} \mathrm{yr}^{-1}$ (N. Graveline et al., Integrated hydroeconomic modelling of water scarcity and salinity under global change: An application to the Gállego river basin (Spain), submitted to the Journal of Hydrology, 2011], supplied by four diversion channels (see the red lines in Figure 5) which collect water from the Ardisa reservoir. In the same period the water demand from the La Violada system was about $53.9 \times 10^{6} \mathrm{~m}^{3} \mathrm{yr}^{-1}$ (N. Graveline et al., submitted, 2011), provided by La Sotonera reservoir through the Monegros channel, which also transfers water to the Eastern Cinca basin (see Figure 5). Water diversions and restitutions are implemented into the model. Gravity and sprinkler irrigation techniques, which are the typical irrigation methods in the Gállego river basin, are implemented within the model by simply adding the irrigation water to the precipitation component in proportion to the irrigated areas of the subcatchment.

[21] For the application of GEOTRANSF, the Gállego basin was subdivided into 233 channels (the mean contributing area of the channels is $17.6 \mathrm{~km}^{2}$ ), with the associated subcatchments (see Figure 4a) aggregated into 6 macroareas (see Figure 5) and streamflow computed at 6 control sections located at the outlet of each macroarea. The selected control sections are located at the 4 reservoirs considered in the study (Lanuza, Bubal, Ardisa and La Sotonera) and at 2 stream gauge stations (Anzanigo and Zaragoza, the latter being the outlet of the river basin).

\subsection{Calibration and Validation}

[22] We use the Nash-Sutcliffe efficiency coefficient (NS) [Nash and Sutcliffe, 1970] $N S=1-\sigma_{e}^{2} / \sigma_{0}^{2}$ to identify the optimal set of parameters and to validate the model, where $\sigma_{0}^{2}$ is the variance of the observed streamflow signal and $\sigma_{e}^{2}$ is the variance of the residuals, which are defined as the difference between the observational data and the model prediction. According to this metric, $N S=1$ when the match between the model and the observational data is perfect and all the residuals are zero. On the other hand, when $N S<0$ the model should be disregarded because its predictions are worse than approximating all the observational data with their sample mean. The search for the optimal set of parameters which maximizes the $N S$ coefficient has been performed by using the Particle Swarm Optimization (PSO) technique [Robinson and Rahmat-Samii, 2004; Castagna and Bellin, 2009; Majone et al., 2010]. PSO is a robust stochastic evolutionary optimization technique based on the movement of a swarm of bees. The application of this algorithm is particularly suited to inverse modeling with many parameters because it avoids trapping in local minima of the objective function, and it is insensitive to both initial conditions and the shape of the objective function.

[23] The calibration and validation procedure was performed by matching daily streamflow data for the period 2001-2005 at the 6 selected control sections shown in Figure 5 (as described above, simulations started in the year 2000). During the calibration of the model, the basin was divided into 6 macroareas, with the output of each macroarea used as input for the successive. This 5 year period shows wide variations in the hydrological regime with two extremely dry years (2002 and 2005) and thus can be considered a severe test of the model. Calibration was performed separately for each of the 5 years of the period 2001-2005 as well as for the entire period, thereby obtaining 6 sets of parameters. Subsequently, the validation was undertaken by running the model on the entire period of observation by using, in turn, the above 6 sets of parameters and computing the NS coefficient separately for each year. These procedures, commonly known as cross validations [see e.g., Kirchner, 2009], are still relatively uncommon in the hydrological modeling literature [Seibert, 2003]. Here we accepted the set of parameters which produced, on average, the highest $N S$ in the validation of the individual years. This has the advantage of evaluating the performance of a set of parameters on single years and excludes sets which could result in a good performance over a single year but bad performance in other parts of the time series. For example, with reference to the section A123-Anzanigo, Table 1 shows that the set of parameters obtained by calibrating the model to the year 2003 produces relatively high- $N S$ values when applied to the remaining years. Furthermore, when applied to the entire 2001-2005 period this set of parameters provided a good reproduction of the streamflow with $N S=0.78$, a value that is only slightly smaller than $N S=0.8$ obtained by calibrating over the 
Table 1. Nash-Sutcliffe Index Values of the Validation Procedure Applied to the Control Section A123-Anzanigo ${ }^{a}$

\begin{tabular}{lcccccc}
\hline & \multicolumn{5}{c}{ Calibration Period } \\
\cline { 2 - 7 } Validation Period & 2001 & 2002 & 2003 & 2004 & 2005 & $2001-2005$ \\
\hline 2001 & $\mathbf{0 . 8 9}$ & 0.82 & 0.79 & 0.83 & 0.73 & 0.85 \\
2002 & 0.36 & $\mathbf{0 . 7 7}$ & 0.72 & 0.53 & 0.31 & 0.73 \\
2003 & 0.54 & 0.66 & $\mathbf{0 . 6 8}$ & 0.58 & 0.52 & 0.68 \\
2004 & 0.72 & 0.62 & 0.66 & $\mathbf{0 . 7 7}$ & 0.66 & 0.68 \\
2005 & 0.60 & 0.55 & 0.73 & 0.68 & $\mathbf{0 . 7 8}$ & 0.69 \\
$2001-2005$ & 0.73 & 0.78 & 0.78 & 0.75 & 0.68 & $\mathbf{0 . 8 0}$ \\
\hline
\end{tabular}

${ }^{\mathrm{a}}$ See Figure 5 .

entire 2001-2005 time series. The streamflow computed at Anzanigo over the period 2006-2008 (not shown here) by using the same set of parameters was in even better agreement with the observational data $(N S=0.82)$, which is slightly higher than the value obtained for the calibration of the period 2001-2005. This is further evidence that the set of data obtained by calibrating to the year 2003 provides a good reproduction of the streamflow recorded in other periods. Notice that the period 2006-2008 was not adopted for the calibration of the hydrological model because a complete data set of streamflow values was not available in all the gauges considered in the present study. Table 1 shows that all the sets of parameters obtained by calibrating on single years produce good results when applied to the 2001-2005 period, as shown by the relatively high values of $N S$ reported in the last row of the table. This suggests that the sets of parameters obtained by calibrating over the single years are all acceptable according to the equifinality principle [Beven and Freer, 2001], although significant reductions of $N S$ are observed in a few single year's validations (see for example the $N S$ value of 0.31 obtained by computing the streamflow of the year 2002 with the parameters obtained by calibrating on the year 2005). Figure 6 compares measured streamflows at the outlet of macroarea 3 over the period 2001-2005 with the results of the model when the model's parameters are obtained by calibrating on the year 2003. We observe that the model correctly reproduces both the timing and shape of the storm events

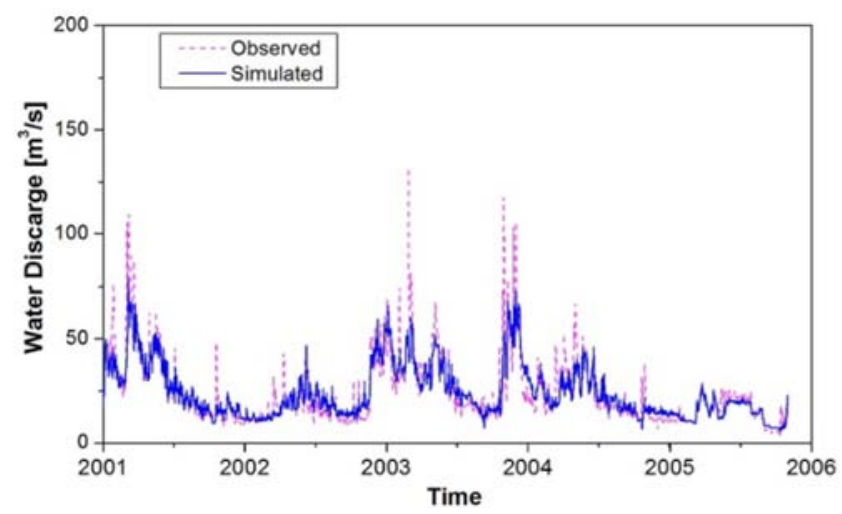

Figure 6. Observed (blue line) versus simulated (pink line) daily streamflow during the period 2001-2005 computed at the outlet of macroarea 3 and obtained by calibrating the model on the year 2003 . and also the recession curve in the period between two consecutive rainfall events, although peak flows are not well reproduced. Since this study focuses on the availability of water resources and not on extreme events we assert that the underestimation of some peak flows do not compromise our conclusions. Similar results are also obtained for the other macroareas and are not shown here. The set of parameters obtained by calibrating to the year 2003 are therefore selected as representative of the macroarea.

[24] Care was taken to model reservoir withdrawals and restitutions to the river system correctly, while the effect of irrigation was introduced according to the inferred protocols. On the basis of observational data for 2000-2005 simplified operational rules at the monthly time scale, which were obtained by dividing the year into two periods: the storage period (October to March), and the irrigation period (April to September) when the water previously stored is used to satisfy the demand from agricultural usage, were reconstructed for each of the four reservoirs (see Figure 5). In the storage period, reservoirs are operated to maximize the storage of water, in particular during periods of snowmelt, while excess water is used for hydropower production. Furthermore, some water is released from the reservoir in order to satisfy minimum flow requirements which are mandatory in hydrological planning (CHE, online, 2007).

[25] La Sotonera and Ardisa, which are regulated for irrigation purposes, exert a strong control on streamflow, in particular La Sotonera which is the reservoir with the highest storage volume $\left(179 \times 10^{6} \mathrm{~m}^{3}\right)$ in the Gállego catchment. For these reservoirs, the monthly water releases have been calculated according to the irrigation demand resulting from the application of a dynamically coupled agroeconomical model (N. Graveline et al., submitted, 2011). The Violada district uses about 1/7 of the volume extracted from La Sotonera by means of the Monegros channel; the remaining volume is utilized by the irrigation districts of the Cinca basin, outside the Gállego catchment. The water stored in the Ardisa reservoir in excess of the minimum value of $1.2 \times 10^{6} \mathrm{~m}^{3}$, which is required in order to guarantee fish survival, is primarily used to deliver water to the lower Gállego (upstream of the Bajo Gállego irrigation district). When the Bajo Gállego irrigation demands are satisfied, the excess water can be transferred to La Sotonera reservoir through the Canal de Gállego. In addition, inflow water into the Ardisa reservoir in excess of $90 \mathrm{~m}^{3} \mathrm{~s}^{-1}$ is stored for successive use.

[26] The Lanuza reservoir is regulated for hydropower purposes and we have assumed that when the stored volume exceeds the threshold value of $7 \times 10^{6} \mathrm{~m}^{3}$, which corresponds to the volume of the minimum regulation level, a constant water discharge of $5.0 \mathrm{~m}^{3} \mathrm{~s}^{-1}$ (CHE, online, 2007) is used for hydropower production. The Bubal reservoir is regulated for both hydropower and irrigation purposes and we have assumed that the volume of water released from the reservoir is $237 \times 10^{6} \mathrm{~m}^{3} \mathrm{yr}^{-1}$ (CHE, online, 2007) concentrated in the irrigation period.

[27] As an example of the capability of the model to simulate the volume stored in the reservoirs, Figure 7 shows the observed (blue line) versus simulated (pink line) daily water volumes for the La Sotonera reservoir during the period 2001-2005. Note that the simplified monthly operational rules we have inferred from the data are able to 


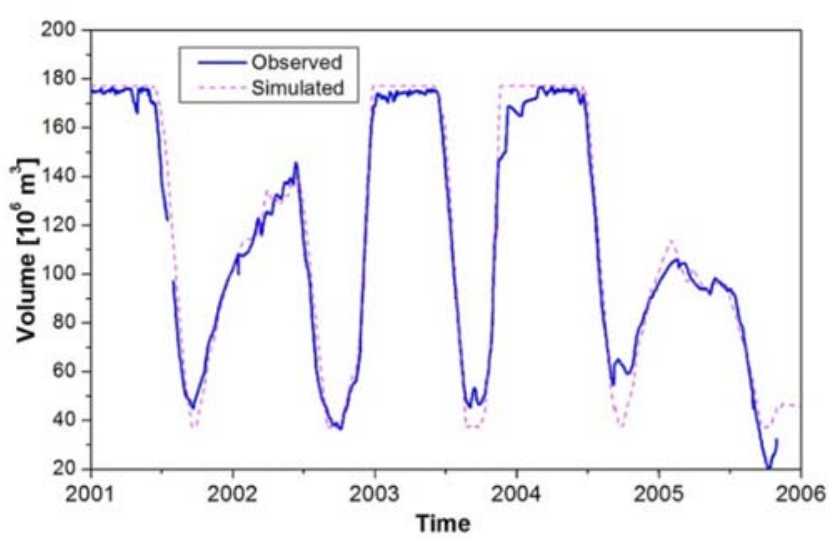

Figure 7. Observed (blue line) versus simulated (pink line) daily water volumes for the E038-La Sotonera reservoir during the calibration period 2001-2005.

reproduce the general behavior of the observed volumes both for the storage and the irrigation periods.

\section{Climate Forcing Data}

\subsection{Downscaled Climate Scenarios}

[28] In this study an ensemble of six RCM experiments from the PRUDENCE project (see Table 2) was used to provide daily temperature and precipitation simulations for the Gállego basin. PRUDENCE provides "time-slice" experiments representing a stationary climate for both control (1961-1990; CTRL) and future (2071-2100; SCEN) periods at a resolution of $\sim 50 \mathrm{~km}$, the latter assuming greenhouse gas and aerosol emissions described by the SRES [Nakícenovíc et al., 2000] A2 (medium-high) scenario. The A2 scenario family is based on a continuously increasing population, relatively slow improvements in energy efficiency and the delayed development of renewable energy. This six-model ensemble was chosen so that uncertainties in the models could be evaluated for the same bounding GCM in combination with different RCMs and the same RCM in combination with different bounding GCMs. Further details on RCM formulations are provided by Jacob et al. [2007]. Boundary conditions in this ensemble are derived primarily from the models $\operatorname{HadAM} 3 \mathrm{H}$ [Gordon et al., 2000; Pope et al., 2000] and ECHAM4/ OPYC [Roeckner et al., 1996] although the HadRM3P and ARPEGE RCM simulations derive boundary conditions from HadAM3P and HadCM3, respectively. It is acknowledged that the range of uncertainty generated by the choice of GCM boundary conditions is constrained by the experimental structure provided by the PRUDENCE project [Déqué et al., 2007]. The PRUDENCE ensemble therefore does not fully examine the RCM-GCM matrix, with only a limited number of GCMs providing boundary conditions, nor does it incorporate the full range of emissions scenarios. In this sense the experimental framework constitutes an "ensemble of opportunity" [Tebaldi and Knutti, 2007] with the size and nature of the ensemble to some degree determined for pragmatic reasons. Nonetheless, the use of such multimodel ensembles allows some assessment of uncertainty in projections of future climate and provides the most robust estimates of future change to date for water resources in this region.

[29] As noted in section 1, RCMs are generally unable to provide data at the resolution required for hydrological simulations and so further bias correction/statistical downscaling procedures are required. The use of correction factors based on monthly relationships between individual observed weather station data and the corresponding grid cell from the RCM control experiment [e.g., Fowler and Kilsby, 2007] is a relatively simple technique which may be applied quickly to simulations from a large number of climate models. Mean monthly differences (for temperature) and ratios (for precipitation) between the CTRL simulations and the point observations are used to correct the daily RCM CTRL and SCEN values. This provides mean bias-corrected scenarios of daily temperature and precipitation downscaled to the point scale and therefore meaningful for input to hydrological models in catchments with varying topography and climatic characteristics. This "biascorrection" assumes that the same model biases persist in the future climate and thus that climate models more accurately simulate relative change than absolute values. However, it provides a correction of monthly mean climate only and does not correct biases in higher order statistics including the simulation of extreme events and persistence. For many impact assessments, e.g., flood hazards, the relevant hydrological phenomena are sensitive to such biases and more sophisticated "quantile mapping" correction or downscaling methods are considered more appropriate. Here, however, we assert that the reproduction of long-term mean flows are of crucial importance for water resources and so bias correction of mean climate is a reasonable approach to take before exploring more sophisticated approaches.

[30] Here, the bias correction method was applied to the six PRUDENCE RCM experiments listed in Table 2 using observed temperature and precipitation data for the period

Table 2. PRUDENCE Regional Climate Models Used in this Study ${ }^{\mathrm{a}}$

\begin{tabular}{lccc}
\hline RCM & Driving GCM & PRUDENCE Acronym & AquaTerra Acronym \\
\hline HIRHAM & HadAM3H A2 & HC1/HS1 & HIRHAM_H \\
HIRHAM & ECHAM4/OPYC A2 & ecctrl/ecscA2 & HIRHAM_E \\
RCAO & HadAM3H A2 & HCCTL/HCA2 & RCAO_H \\
RCAO & ECHAM4/OPYC A2 & MPICTL/MPIA2 & RCAO_E \\
HadRM3P & adeha/adhfa & HAD_H \\
Arpège & HadCM3 A2 2 & DA9/DE6 & ARPEGE_H \\
\hline
\end{tabular}

${ }^{\text {a }}$ The acronyms adopted in the AquaTerra project [Gerzabek et al., 2007] are used here however the corresponding PRUDENCE acronyms are provided for reference. The first part of each acronym refers to the RCM and the second to the GCM data used to provide the boundary conditions (see main text). 
1961-1990 for 47 suitable gauging stations within the Gállego subbasin. This produced 6 CTRL and 6 SCEN biascorrected daily time series of precipitation and temperature for each gauging station location for input to the hydrological model. Comparisons of the uncorrected RCM CTRL data to interpolated point observations of mean monthly precipitation and temperature can be found in Bovolo et al. [2011]. In summary, seasonal variations are captured relatively well by the RCMs in all cases, although for some models absolute biases are large. However, differences between the ensemble members decrease and the agreement between RCMs and observations is better for the lower Gallego.

\subsection{Projected Changes in Climate}

[31] Projected changes in the bias-corrected RCM output for the period 2071-2100 for the Gállego basin are shown in Figure 8. There is a projected decrease in precipitation throughout most of the year, with some RCMs projecting a slight increase between December and February during the storage period. All RCM experiments project much lower precipitation during the irrigation period though in some months the ensemble range is large, for example decreases from $-3.6 \%$ (RCAO_H) to - 70.4\% (RCAO_E) in April. Overall, mean annual precipitation is projected to decrease between $-24 \%$ and $-49 \%$ over the whole Gállego basin. The ensemble also suggests that mean temperatures in the Gállego region will increase substantially throughout the
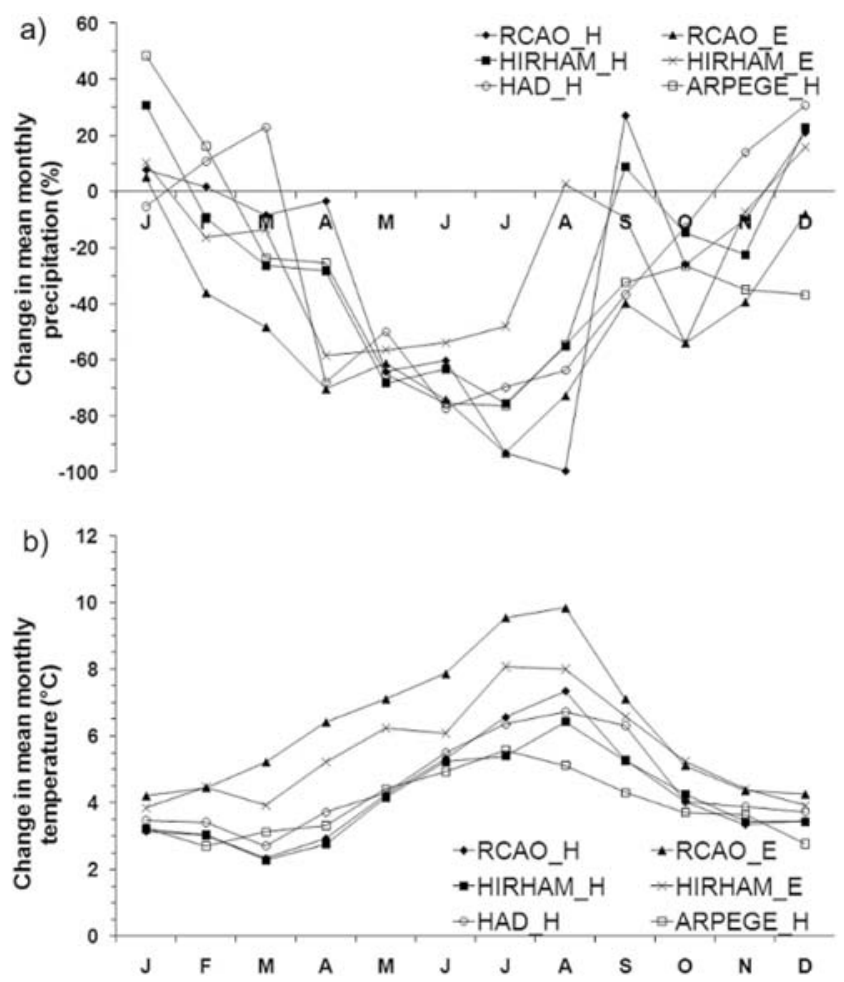

Figure 8. Projected change in (a) mean precipitation and (b) temperature for the Gállego river basin for the period 2071-2100. Changes in precipitation are expressed as a percentage of the 1961-1990 means while temperature is presented as absolute change. year with an average increase of between $+3.9^{\circ} \mathrm{C}$ and $+6.3^{\circ} \mathrm{C}$. The lowest increase in temperature occurs in December and January $\left(3.1^{\circ} \mathrm{C}\right.$ to $\left.4.2^{\circ} \mathrm{C}\right)$ while the largest increases occur during the irrigation period in July and August $\left(5.1^{\circ} \mathrm{C}\right.$ to $\left.9.8^{\circ} \mathrm{C}\right)$. Figure 8 indicates that the driving GCM is an important source of uncertainty as the experiments driven by boundary conditions provided by ECHAM4 project the largest increases. For example, RCAO_E projects an increase of the mean temperature in summer months of $9.8^{\circ} \mathrm{C}$. Climate change projections derived from the PRUDENCE ensemble for the Gállego are discussed in greater detail by Bürger et al. [2007] and Bovolo et al. [2011].

\section{Validation of Hydrological Flows for the CTRL Period, 1961-1990}

[32] In principle, an idealized model and calibration procedure should lead to a set of parameters which are independent from the period of calibration. However, in practice, none of the many conceptual models and parameterizations proposed in existing hydrological models are completely independent of the period of calibration [Yapo et al., 1996], and this is also the case for GEOTRANSF. Consequently, it is essential to validate the model calibrated using observed streamflow for the period 2000-2005 by verifying that it is able to reproduce available observed streamflow for 1961-1990.

[33] Table 3 demonstrates the different climatic conditions which characterize the two periods. The period 2000 2005 experienced about $20 \%$ less precipitation annually with respect to the 1961-1990 period and much less during the second half of the storage period. Average annual precipitation totals during the calibration period are close to those projected for the long-term SCEN climate average by the ensemble mean, while the annual mean temperature for the calibration period was also $\sim 1.5^{\circ} \mathrm{C}$ warmer than the control period (not shown). The climate for the calibration period thus exhibits the general characteristics of the projected future climate, i.e., drier and warmer.

[34] As a first step in the validation procedure, we ran the model for the CTRL period using, as input, the observed meteorological data used to bias-correct the RCM outputs and the parameters obtained by the calibration procedure described in section 3.2. Since data allowing the inference of operational rules for reservoirs are not available for 19611990 , the same rules as those inferred for the model calibration period, 2000-2005, were used for the simulations. For the model runs, the Lanuza and Bubal reservoirs were considered to have started their operations in 1982 and 1971, respectively. Furthermore, the year 1961 was used as a spin-up period for the hydrological simulations in order to obtain a correct initialization of all the fluxes within each subcatchment.

[35] The only stream-gauge with a long-streamflow time series within the CTRL period is Anzanigo, with observations available for 1 April 1971 to 31 December 1990. Comparisons between the daily streamflow data at Anzanigo during this period and the corresponding model simulations using parameters obtained during the calibration procedure described in section 3.2, resulted in a Nash-Sutcliffe coefficient of $N S=0.43$. We consider this acceptable, considering that the performance increases to $N S=0.68$ in the period 1 
Table 3. Average Precipitation for the Gállego for the Observed and Bias-Corrected RCM Future ${ }^{\mathrm{a}}$

\begin{tabular}{lcccccc}
\hline & & \multicolumn{2}{c}{ Storing } & & \multicolumn{2}{c}{ Irrigation } \\
\cline { 3 - 4 } \cline { 5 - 7 } & Annual & OND & JFM & & AMJ & JAS \\
\hline OBS Control (1961-1990) & 788 & 237 & 188 & & 218 & 145 \\
OBS Calibration (2000-2005) & $617(-21.7 \%)$ & $224(-5.4 \%)$ & $120(-36.3 \%)$ & & $162(-25.6 \%)$ & $111(-23.7 \%)$ \\
RCM SCEN (2071-2100) & $632(-19.8 \%)$ & $210(-11.5 \%)$ & $185(-1.3 \%)$ & & $135(-38.0 \%)$ & $101(-30.2 \%)$ \\
\hline
\end{tabular}

\footnotetext{
${ }^{a}$ Observed (OBS) means are shown for both the RCM control (CTRL) and hydrological model calibration periods, RCM future (SCEN) shows the en-
} semble average precipitation (in $\mathrm{mm}$ ). Figures in brackets denote deviations from the observed control period means.

April 1971 to 31 December 1990 when the uncertainty associated with the reservoir functioning rules are filtered out by assigning the measured outflow from the Bubal reservoir located further upstream (see Figure 5). The ability of the model to provide simulations free of bias can also be assessed by plotting the observed versus simulated streamflow, as shown in Figure 9 for Anzanigo. Points are grouped symmetrically around the diagonal line, with an average error of $2.25 \mathrm{~m}^{3} \mathrm{~s}^{-1}$ and a correlation coefficient of 0.77 between simulated and observed values. Even though the performance may not be optimal this is an indication that the model does not introduce bias in the simulations. If the comparison between simulated and observed values at Anzanigo is performed by assigning observed values to the water outflows from the Bubal reservoir, the average error decreases to $1.76 \mathrm{~m}^{3} \mathrm{~s}^{-1}$ and the correlation coefficient increases to 0.83 .

[36] River authorities often refer to flow duration curves (FDCs) as a useful tool for assessing the availability of water resources and for calculating withdrawal rules, such as the minimum water discharge that should not be surpassed in the presence of withdrawals and the marginal cost related to the increase of the maximum water discharge that can be diverted from a river. Here, FDCs are used to assess differences in the probability distribution at low, intermediate and high flows between simulated and observed streamflow and between actual and modeled future streamflow. Following Yilmaz et al. [2008] we identify low flows as those with a probability of exceedance larger than 0.7 , intermediate flows as those with probability

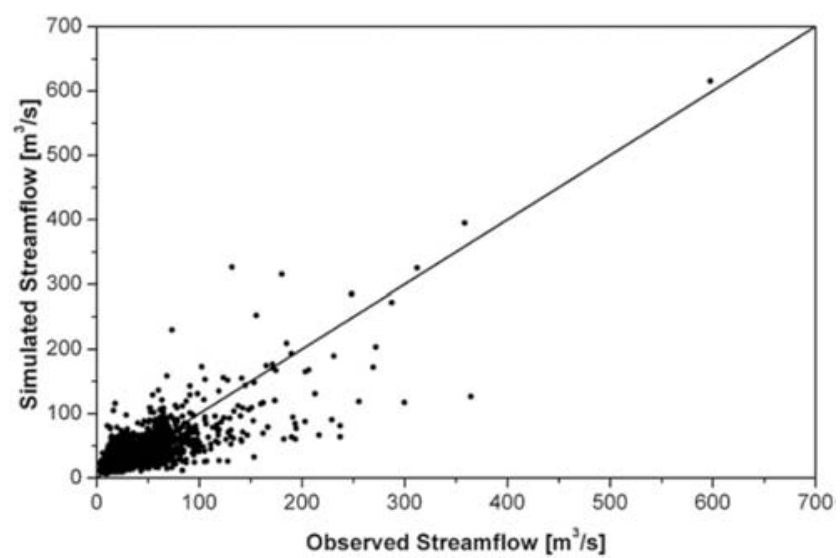

Figure 9. Scatterplot of observed against simulated streamflow at the Anzanigo gauging station during the period 1971-1990. of exceedance in the range $0.2-0.7$ and high flows as those with probability of exceedance smaller than 0.2 .

[37] Figure 10 compares FDCs for observed and simulated daily streamflow from 1 April 1971 to 31 December 1990 at Anzanigo for the whole year, for the irrigation period only (April to September) and for the storage period only (October to March). For the irrigation period the observed FDC curve is slightly higher (i.e., for a given probability of exceedance it leads to a higher water discharge) than for the storage period, while the annual FDC is always between the two. These differences, appreciable at low flows, reduce progressively as flow increases, and become undetectable at high flows. This result was expected given that the Bubal reservoir is operated in such a way as to store water in winter (thus reducing low and intermediate flows) and to deliver it in summer during the irrigation period. High flows are barely modified by the reservoir, possibly because they occur preferentially when the volume needed for irrigation is already stored and water can be used for hydropower production. Simulated FDCs show a similar behavior, with the exception of high flows where small detectable differences are present, and are in good agreement with the observed FDC curves for high flows, however simulated intermediate to low flows are

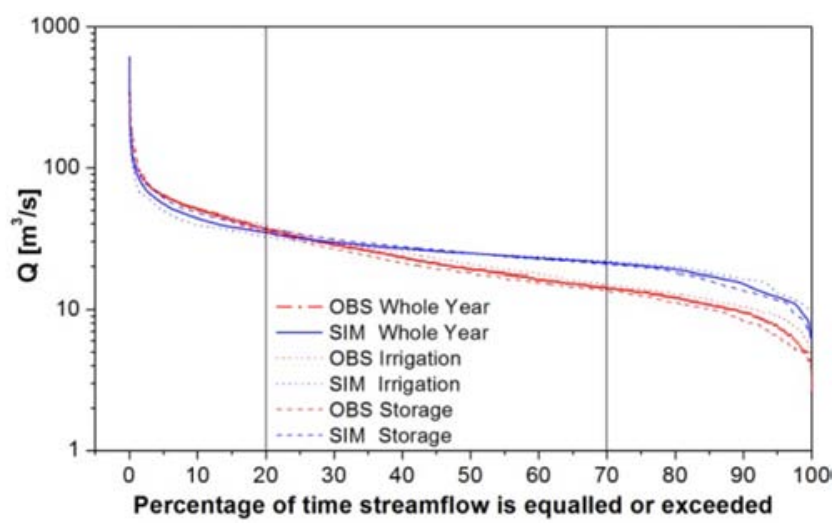

Figure 10. Observed (red lines) and simulated (blue lines) FDCs calculated at the Anzanigo node for 1 April 1971 to 31 December 1990 for the whole year (solid lines), the storage period only (dashed lines) and the irrigation period only (dotted lines). The vertical black lines divide the curves into three portions corresponding to different flow magnitudes: high flows $(0 \%-20 \%)$, medium flows $(20 \%-70 \%)$ and low flows $(70 \%-100 \%)$. Note that the streamflows are plotted on a log scale which emphasizes differences in low flows. 
higher than observed flows. These differences are due to modeling errors, but also to the uncertainty introduced by applying to the Bubal reservoir operational rules inferred during the calibration period.

[38] As a second step in the validation procedure, we ran the hydrological model for the CTRL period using, as input, the bias-corrected CTRL RCM data for a selection of three RCMs: RCAO_E, a relatively low-precipitation model compared with other RCMs; RCAO_H, a relatively high-precipitation model; and HIRHAM_E, which shows the highest variability of monthly precipitation totals. This sub sample of models covers, to a limited extent, sensitivity to the choice of both RCM and GCM. The hydrological model was also run using observed meteorological forcing for 1961-1990 in order to assess the skill of the RCM CTRL simulations in reproducing the simulation forced by observed data (see Figure 11). Seasonality of streamflows, as described by the variation of the monthly means, is well reproduced by all three RCMs when compared with simulations forced by observed data, with only limited differences in October and November, probably due to the impact of floods which are not well captured by the RCMs. Furthermore, the three RCMs reproduce the low variability of streamflow in summer (due to scarcity of precipitation), the larger variability in autumn and winter and the increase of variability in May due to convective rainfall well (see also Figure 2). In general, the RCMs produce a lower variability in daily streamflow than the simulation forced by observations, and some differences are observed among the RCMs. These differences are likely to be due to their different parameterizations and the GCMs used to establish the boundary conditions. However, they are small and the simulations demonstrate that the framework we have established by coupling RCMs with a hydrological model has some skill in reproducing the hydrological signal of the CTRL period at both Anzanigo and Zaragoza. Furthermore, the FDCs for the simulations shown in Figure 11 result in almost indistinguishable curves (not shown here). Given this result, hereafter the projections resulting from the six bias-corrected RCM outputs adopted in this study will be compared on a RCM by RCM basis with the results of the hydrological simulations of the CTRL period forced by bias-corrected RCM forcing.

\section{Results}

[39] In section 6 we investigate the impact of climate change on the hydrological system and water management of the Gállego basin. Specifically, we compare changes in daily streamflow at Anzanigo and Zaragoza. We then analyze the likely changes in water resources management at La Sotonera reservoir, an important large reservoir which provides $65 \%$ of the storage capacity of the irrigation systems fed by the Gállego river (CHE, online, 2007), triggered by changes in the hydrological and streamflow regimes.

[40] Simulations were conducted for the period 20712100 , with the projected daily time series of bias-corrected precipitation and temperature derived from the RCMs as described in section 4. Hydrological simulations, using GEOTRANSF, were conducted using parameters calibrated on the period 2000-2005 and the management rules for the Ardisa and La Sotonera reservoirs provided by the coupled agroeconomical model developed in the work of $\mathrm{N}$.
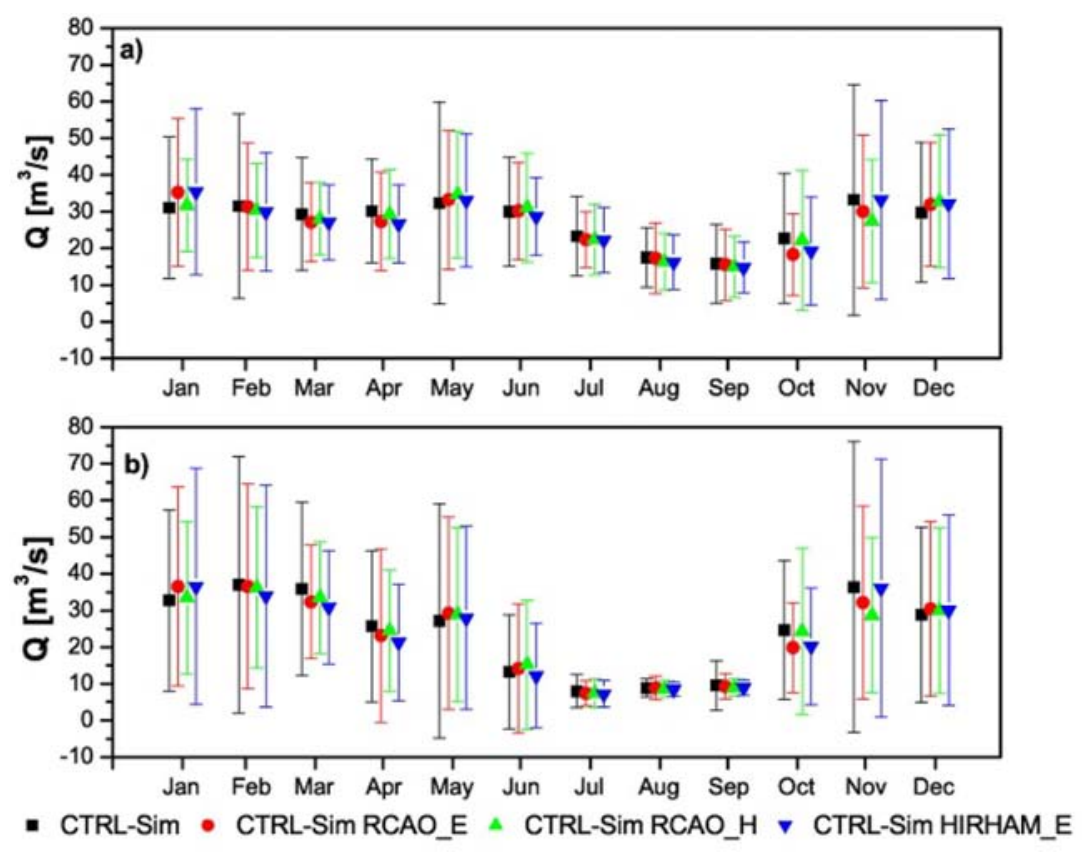

Figure 11. Monthly average streamflow (symbols) and 2 standard deviation confidence intervals (lines) at (a) Anzanigo, and (b) Zaragoza, for three different RCMs during the CTRL period, 1961-1990. The statistics for each month are calculated from daily simulated streamflow values obtained by using the bias-corrected CTRL precipitation and temperature time series as external forcing. Simulated streamflows calculated by using the observed precipitation and temperature time series as external forcing are shown in black. 
Graveline et al. (submitted, 2011). Under normal conditions the farmers base their crop choice on the CHE future water availability forecast provided at the end of the winter (typically on 1 March), which to a large extent fixes the water demand during the following irrigation season. Future scenarios in term of water request from the agricultural activities are performed assuming zero forecasting errors and that farmers are able to choose the optimal crop mix for that particular year. The implications of this assumption are that the crop choices are directly linked to the total reservoir inflow during the storage period and consequently determine the real water demand and the releases of water from the reservoirs.

\subsection{Effects of Climate Change on the Hydrological System}

[41] Simulated FDCs at Anzanigo and Zaragoza during the 2071-2100 time slice are shown in Figure 12 and Figure 13, respectively. Since CTRL RCM simulations for both stations result in indistinguishable curves for the simulation conducted with the observed meteorological forcing, we only show the latter FDC as representative of the CTRL period runs in both figures. As already mentioned, the projected changes are in any case calculated on a RCM by RCM basis. For Anzanigo, a downward shift in the FDCs is projected (see Figure 12a), implying a nearly uniform reduction of projected streamflow. However, all RCMs project an increased frequency of low flows, i.e., flows with probability of exceedance larger than $95 \%$, with respect to the RCM CTRL runs which we attribute to alterations of the low flow regime caused by the Bubal reservoir which started its operations in 1971. Reductions in mean streamflow of between $-13.2 \%$ (for HIRHAM_H) and $-33.2 \%$ (for RCAO_E), compared with the RCM CTRL runs (see Table 4) are projected and reflect the changes in daily precipitation and mean temperature projected by the RCMs. In particular, the projections from RCAO_E show the largest deviation from the CTRL period with a significant reduction of water discharge throughout the entire range of variability. In general, the projected reductions (see Figure 12a and Table 4) are larger for streamflows derived from RCAO_E, HIRHAM_E and ARPEGE_H, than those derived from RCAO_H, HAD_H and HIRHAM_H. This demonstrates that the driving GCM represents a substantial source of uncertainty to future streamflow projections, in addition to that arising from the RCM model itself (the climate response shown in section 4). This is consistent with studies of climate change impacts on UK rivers which have highlighted the importance of GCM uncertainty relative to other sources [e.g., Prudhomme and Davies, 2009; Kay et al., 2009].

[42] Seasonal differences in projected climate change between RCMs produce variations in the distribution of change in streamflow. We investigated the impact of seasonal change by dividing the year into two periods: the irrigation period, from April to September, and the storage period, which covers the remaining months. The projected FDCs at Anzanigo for the storage and irrigation periods during the 2071-2100 time slice are presented in Figure 12b and Figure 12c, respectively, together with the FDC of the simulated streamflow for the CTRL period. During the storage period, SCEN simulations project a reduction of
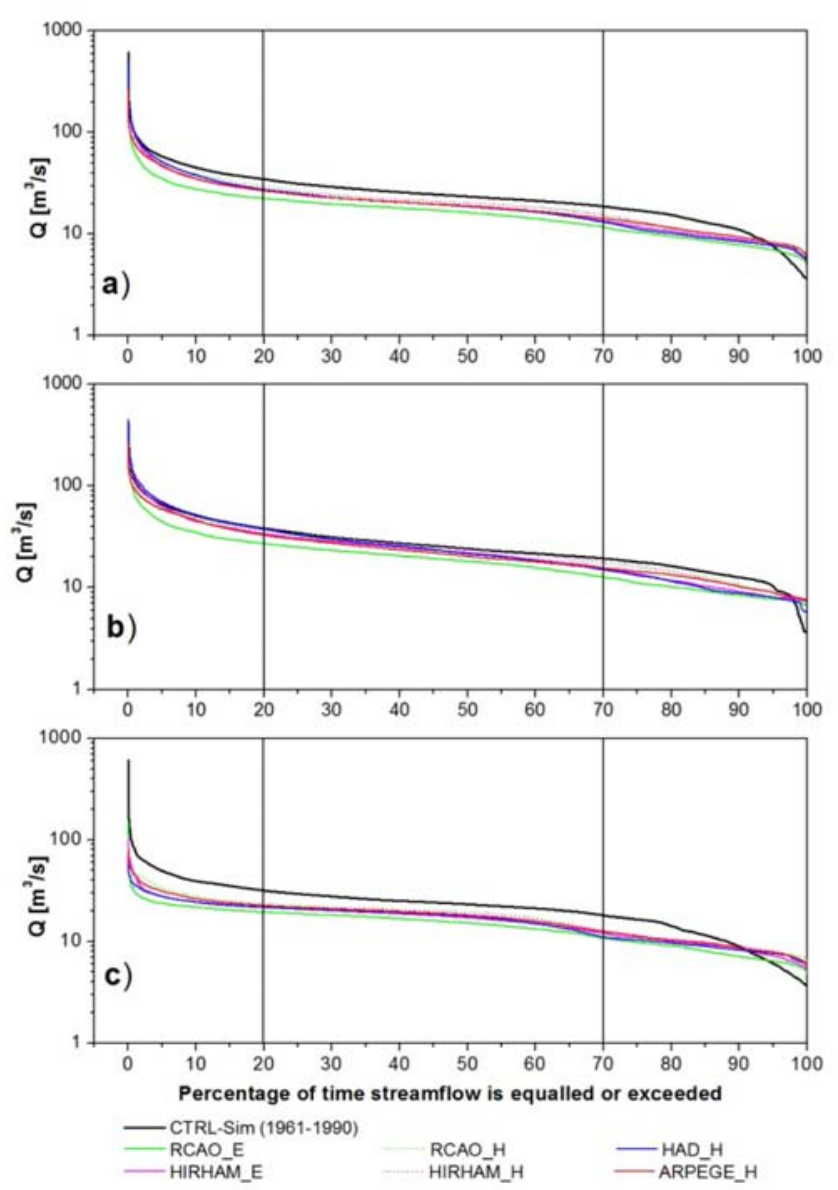

Figure 12. Simulated FDCs calculated at the Anzanigo node for (a) the whole year, (b) the storage period, and (c) the irrigation period, for the six different RCM models adopted in the study for 2071-2100. The black lines show the FDCs of the simulated streamflows calculated for the same operational periods during the CTRL period 19611990. The vertical black lines divide the curves into three portions corresponding to different flow magnitudes: high flows $(0 \%-20 \%)$, medium flows $(20 \%-70 \%)$, and low flows $(70 \%-100 \%)$. Note that the streamflows are plotted on a log scale which emphasizes differences in low flows.

streamflow in the range between medium to low flows with respect to the CTRL period, while high flows are projected to be generally unaltered with the exception of simulations forced by the RCAO_E and HIRHAM_E RCMs, which predict a reduction in high flows. During the irrigation period, all RCMs project a reduction of streamflow across the entire range of flows.

[43] The percentage reductions in mean streamflow projected for 2071-2100 with respect to 1961-1990 range from $-1.5 \%$ (HIRHAM_H) to $-28.0 \%$ (RCAO_E) for the storage period, and are higher, from $-24.1 \%$ (RCAO_H) to $-39.4 \%$ (RCAO_E) for the irrigation period (see Table 4). This is in agreement with the seasonal changes in climatic variables projected by the RCMs, which indicate larger relative reductions of precipitation and larger increases of temperature during the irrigation period than during the storage period. Visual inspection of Figure $12 \mathrm{~b}$ and Figure 12c also 
Table 4. Simulated Average Daily Streamflows at the Anzanigo and Zaragoza Gauging Station for 1961-1990 and 2071-2100

\begin{tabular}{|c|c|c|c|c|c|c|}
\hline \multirow[b]{2}{*}{ Scenario } & \multicolumn{3}{|c|}{ Anzanigo } & \multicolumn{3}{|c|}{ Saragoza } \\
\hline & $\begin{array}{l}\text { Annual } \\
\left(\mathrm{m}^{3} \mathrm{~s}^{-1}\right)\end{array}$ & $\begin{array}{l}\text { Storing }\left(\mathrm{m}^{3} \mathrm{~s}^{-1}\right) \\
\text { ONDJFM }\end{array}$ & $\begin{array}{c}\text { Irrigation }\left(\mathrm{m}^{3} \mathrm{~s}^{-1}\right) \\
\text { AMJJAS }\end{array}$ & $\begin{array}{l}\text { Annual } \\
\left(\mathrm{m}^{3} \mathrm{~s}^{-1}\right)\end{array}$ & $\begin{array}{l}\text { Storing }\left(\mathrm{m}^{3} \mathrm{~s}^{-1}\right) \\
\text { ONDJFM }\end{array}$ & $\begin{array}{c}\text { Irrigation }\left(\mathrm{m}^{3} \mathrm{~s}^{-1}\right) \\
\text { AMJAS }\end{array}$ \\
\hline CTRL (1961-1990) & 27.2 & 29.6 & 24.8 & 24.0 & 32.5 & 15.4 \\
\hline CTRL RCAO_E & 26.7 & 29.0 & 24.4 & 26.7 & 29.0 & 24.4 \\
\hline CTRL RCAO_H & 26.7 & 28.7 & 24.8 & 26.7 & 28.7 & 24.8 \\
\hline CTRL HIRHAM_E & 26.5 & 29.5 & 23.6 & 26.5 & 29.5 & 23.6 \\
\hline CTRL HIRHAM_H & 26.6 & 28.8 & 24.4 & 26.6 & 28.8 & 24.4 \\
\hline CTRL HAD_H & 27.3 & 29.0 & 25.6 & 27.3 & 29.0 & 25.6 \\
\hline CTRL ARPEEGE_H & 26.9 & 29.2 & 24.5 & 26.9 & 29.2 & 24.5 \\
\hline RCAO_E (2071-2100) & $-33.2 \%$ & $-28.0 \%$ & $-39.4 \%$ & $-66.0 \%$ & $-58.4 \%$ & $-81.3 \%$ \\
\hline RCAO_H (2071-2100) & $-14.1 \%$ & $-5.4 \%$ & $-24.1 \%$ & $-30.4 \%$ & $-22.8 \%$ & $-45.4 \%$ \\
\hline HIRHĀM_E (2071-2100) & $-20.9 \%$ & $-10.6 \%$ & $-28.5 \%$ & $-39.1 \%$ & $-29.5 \%$ & $-59.7 \%$ \\
\hline HIRHAM_H (2071-2100) & $-13.2 \%$ & $-1.5 \%$ & $-27.0 \%$ & $-30.5 \%$ & $-19.5 \%$ & $-53.1 \%$ \\
\hline HAD_H (2071-2100) & $-18.5 \%$ & $-4.0 \%$ & $-34.9 \%$ & $-36.5 \%$ & $-23.8 \%$ & $-61.9 \%$ \\
\hline ARPEGE_H (2071-2100) & $-20.2 \%$ & $-14.1 \%$ & $-27.6 \%$ & $-41.5 \%$ & $-35.3 \%$ & $-54.7 \%$ \\
\hline
\end{tabular}

${ }^{\mathrm{a}}$ Values are reported for the three different operational periods: annual, storage and irrigation periods. RCM averages for 2071-2100 are expressed in terms of percentage anomalies with respect to the associated RCM CTRL simulation.

suggests that the spread of the projected FDCs is slightly wider during the storage period, providing evidence that the uncertainty associated with climate modeling is larger in the storage than in the irrigation period.

[44] FDCs at Zaragoza are shown in Figures 13a, 13b, and $13 \mathrm{c}$ for the annual, storage and irrigation periods, respectively, and the corresponding percentage changes in mean streamflow are reported in Table 4. For the annual period all RCMs project lower streamflows with respect to CTRL, with the exception of high flows. Projected changes in the daily streamflow with respect to CTRL are, in percentage terms, larger than those for Anzanigo with reductions ranging from -30.4\% (RCAO_H) to $-66.0 \%$ (RCAO_E). Possible causes for this include: (1) Zaragoza is located in the southern part of the river basin which shows the largest projected decrease in precipitation and increase in temperature for all RCMs; and (2) the streamflow regime in Zaragoza is strongly altered by water diversions in the middle part of the catchment. In particular, the priority rules adopted for the Ardisa reservoir prescribe that once the demand from the Bajo Gállego irrigation district is satisfied all the water in excess of the minimum ecological flow is transferred to La Sotonera reservoir through the Canal de Gállego. Consequently, streamflow downstream of Ardisa exceeds the minimum ecological flow only when la Sotonera is full and the demand from the Bajo Gállego is satisfied. In 2071-2100 this is likely to become an even rarer occurrence due to the projected reductions in streamflow. Similarly to the results for Anzanigo, the Hadley-driven RCMs (with the exception of ARPEGE_H) show the smallest change from the CTRL simulations, while RCAO_E and HIRHAM_E project the largest streamflow reductions.

[45] The projected reductions during the storage period at Zaragoza are larger for medium and low flows than for high flows. During the irrigation period all the RCMs project a significant reduction through the complete range of the simulated flows. During the storage period, mean streamflow is projected to decrease from $-19.5 \%$ (HIRHAM_H) to $-58.4 \%$ (RCAO_E) with respect to 1961 1990, while much larger decreases, ranging from $-45.4 \%$ (RCAO_H) to $-81.3 \%$ (RCAO_E), are projected for the irrigation period (Table 4). Furthermore, during both the storage and irrigation periods the RCAO_E model is by far the driest and hottest ensemble member.

\subsection{Effects of Climate Change on Irrigation}

[46] The projected changes in water resources availability for 2071-2100 with respect to 1961-1990 for the Bajo Gállego, La Violada and Monegros irrigation districts were analyzed. Simulations show that water demand for the Bajo Gállego irrigation district is always satisfied, when evaluated using the socioeconomical model developed by $\mathrm{N}$. Graveline et al. (submitted, 2011). This is a consequence of the management rules adopted for the Ardisa reservoir (section 3.2) which assign priority to the irrigation districts located downstream of the reservoir. In contrast, La Violada and Monegros districts, which are supplied by La Sotonera reservoir through the Monegros channel, are strongly impacted by the projected changes in climate. In subsequent discussions, La Violada and Monegros districts will be considered as a single system.

[47] A first important indicator of the impact of climate change on the La Violada-Monegros system is the inflow to La Sotonera reservoir. Figure 14 shows the projected total annual inflow volume to La Sotonera reservoir (blue line) for 1961-1990 and 2071-2100 for the 6 RCM experiments. The horizontal solid black line indicates the maximum volume of water required from the irrigation system connected to this reservoir (this is an estimate obtained with the agroeconomic model developed by N. Graveline et al. (submitted, 2011)). Above this volume, it is assumed that farmers do not change their crop choice, and thereby water is not a constraining factor for agriculture. All RCMs project a decrease in the inflow to La Sotonera, accompanied by an increase in the frequency of dry years where the annual inflow is below the maximum demand for agriculture $\left(421.6410^{6} \mathrm{~m}^{3}\right)$. The projected number of years for which the inflow to La Sotonera is above this threshold is reported in Table 5. This ranges from 3 to 15 years for RCAO_E and HIRHAM_H, respectively, in sharp contrast to CTRL, where this volume is exceeded in the range of 25 to 26 out of 30 years. Table 5 further confirms that 

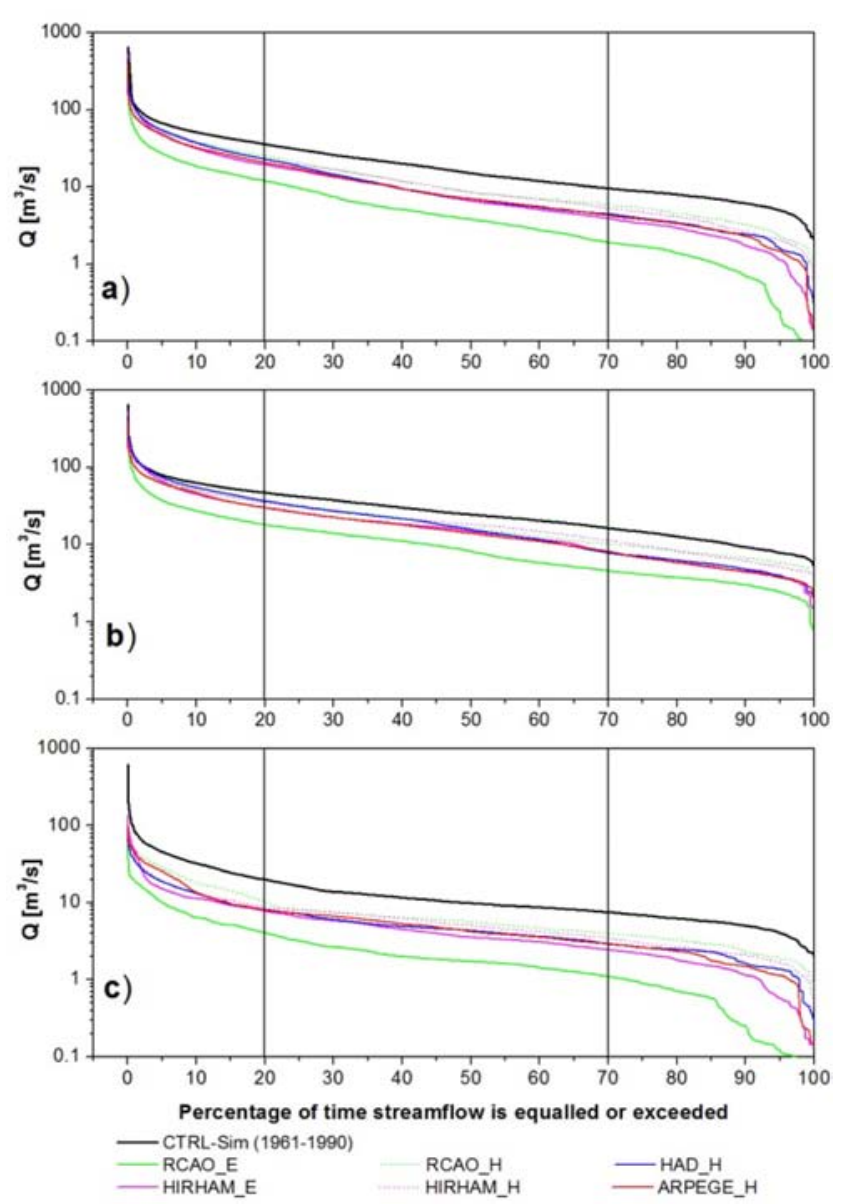

Figure 13. Simulated FDCs calculated at the Zaragoza node during (a) the whole year, (b) the storage period, and (c) the irrigation period for the six different RCM models adopted in the study for 2071-2100. The black lines show the FDCs of the simulated streamflows calculated for the same operational periods during the CTRL period 19611990. The vertical black lines divide the curves into three portions corresponding to different flow magnitudes: high flows $(0 \%-20 \%)$, medium flows $(20 \%-70 \%)$, and low flows $(70 \%-100 \%)$. Note that the streamflows are plotted on a log scale which emphasizes differences in low flows.

RCAO_E projects by far the most severe climate change impacts within the RCM ensemble and that the ECHAMdriven models project larger streamflow reductions with respect to the Hadley-driven RCMs. The projected inflow reduction at La Sotonera is confirmed by visual inspection of Figure 14 and by comparing the CTRL RCM average annual inflow for 1961-1990, with the projected RCM averages for 2071-2100. Relative changes range between $-19.4 \%$ (RCAO_H) and $-34.1 \%$ (RCAO_E).

[48] In the hydrological simulations, the annual agricultural water demand is calculated with the agroeconomic model and depends on the inflow volume to the reservoir. During 1961-1990 inflow is seldom smaller than the maximum demand; however, for 2071-2100 this is a more frequent occurrence. Most likely this scenario would impose a change in crop or irrigation strategy for both the Monegros and La Violada districts. This dramatic shift in water availability is the consequence of the strong reduction in summer precipitation projected by all the RCMs, which is only partially balanced by higher winter precipitation projected by a few RCMs. The impact of this shift in water resources availability on agricultural activities is beyond the objectives of the present work and is detailed in the paper by N. Graveline et al. (submitted, 2011). However, one effect is immediately evident: the projected change in seasonality of precipitation causes for some RCMs a faster filling of the reservoir in winter, with spilling occurring more frequently than in 1961-1990, accompanied by a more rapid reduction of the stored volume in summer when the irrigation systems need to rely more on the stored water because of the reduction in concurrent streamflow. In other words, the change in seasonality of precipitation reduces the efficiency of the whole irrigation system. Total annual precipitation is smaller in 2071-2100 than in 1961-1990. This reduction of total annual inflow to the reservoir coupled with the change in seasonality explains why the annual volume exported by the Monegros channel is often lower than the maximum water demanded by agriculture, though the annual incoming fluxes are above this threshold (see the pink lines in Figure 14). This situation occurred rarely in the 1961-1990 period and in the time slice 2071-2100 when the ECHAM-driven RCMs are used. However, when the Hadley-driven RCMs are used the frequency of this event increases (see Table 5), and this is essentially due to the fact that, within the ensemble adopted in the present study, the Hadley-driven RCMs are the only models projecting increases in winter precipitation with respect to the 19611990 period.

[49] The reduction in efficiency of La Sotonera reservoir is better evidenced in Figure 15, which shows the annual volume duration curves (VDCs) for 1961-1990 and 20712100 for all 6 RCMs. These curves show the percentage of time, with respect to the period of simulation, in which the storage is larger than a given volume. The projected VDCs suggest a substantial reduction of storage in line with the projected reduction of inflows to La Sotonera (see Table 5). During the storage period all RCMs project a reduction in the stored volume with respect to 1961-1990. This projected reduction is particularly severe for RCAO_E. Here, storage reaches its maximum value for only $2 \%$ of the time, compared to $30 \%$ of the time for 1961-1990. For the other RCMs this figure is about $10 \%$ of the time, which is still a significant reduction with respect to the value of about $30 \%$ obtained for the different CTRL RCM runs (see Figure 15b). Projections for the irrigation period, shown in Figure $15 \mathrm{c}$, also suggest an increased probability of very low storage volumes. In particular, the sharp drop of the VDCs at the $90 \%$ probability of exceedance suggests that during the irrigation period water availability from $\mathrm{La}$ Sotonera reduces to zero with the consequence that the agricultural water demands of the La Violada-Monegros system cannot be satisfied.

[50] Impacts on agriculture can be quantified for the La Violada-Monegros system if the projected changes of water delivered from La Sotonera reservoir (see Table 5) are considered. The RCMs project a reduction of available water of between $-3.3 \%$ (RCAO_H) and - $15.7 \%$ (RCAO_E) with respect to 1961-1990. Hence, farmers will be restricted in 

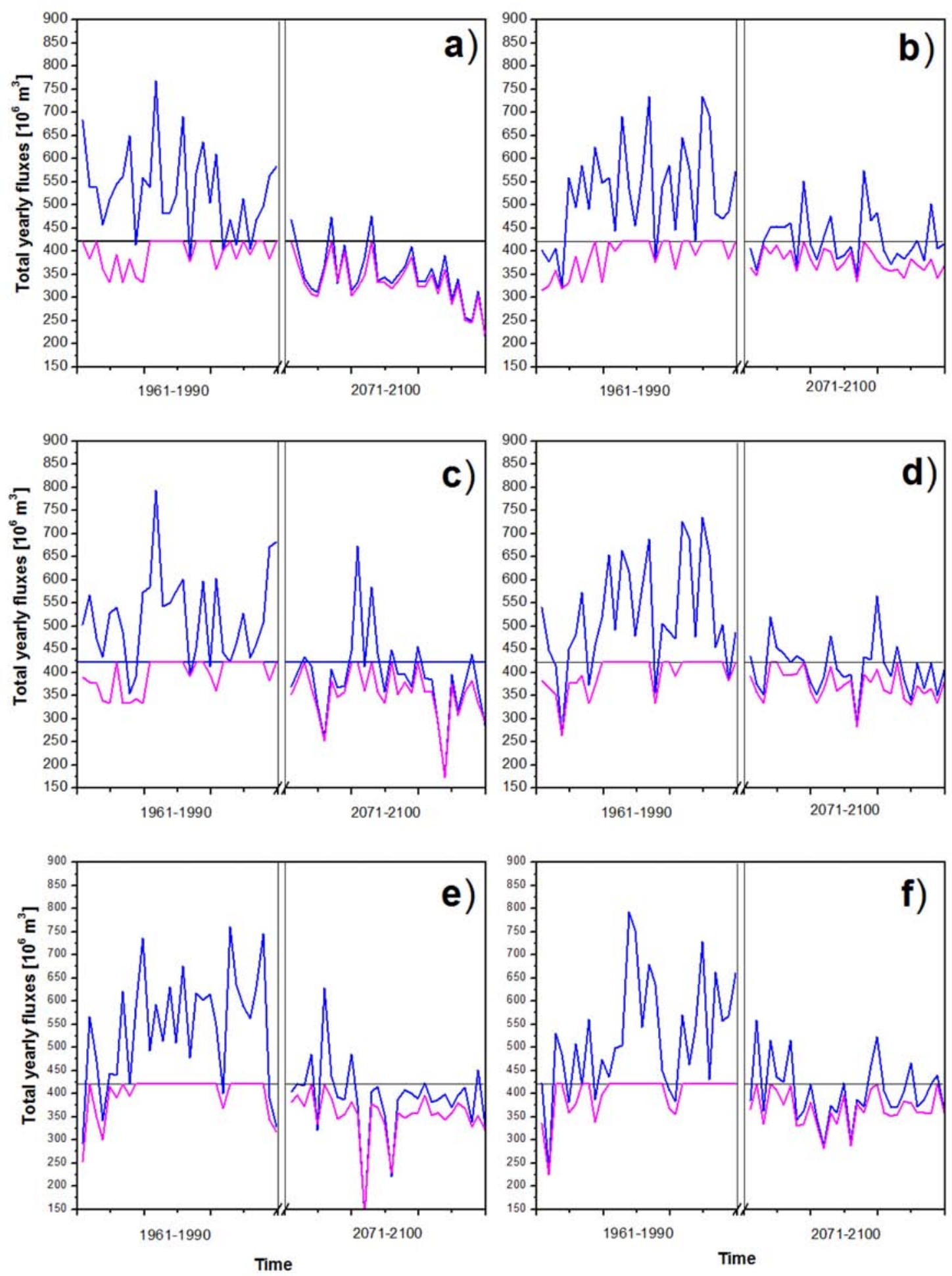

Figure 14. Total yearly inflow to the La Sotonera reservoir (blue line) compared to the withdrawal from the reservoir to feed the Monegros channel (pink line) for the CTRL period 1961-1990 and for the SCEN timeslice 2071-2100, obtained with the RCM models: (a) RCAO_E, (b) RCAO_H, (c) HIRHAM_E, (d) HIRHAM_H, (e) HAD_H, and (f) ARPEGE_H. The climate simulations are stationary representations over the 30 year period. The horizontal black line represents the threshold level of $42110^{6} \mathrm{~m}^{3}$ which is the maximum value of water availability required from the irrigation districts connected to the La Sotonera reservoir (estimate obtained with the agroeconomic model developed in the work of N. Graveline et al. (submitted, 2011)). Below this threshold water availability becomes a constraining factor to farmers. 
Table 5. Mean Annual Inflow to the La Sotonera Reservoir and Effective Delivery to the Monegros Channel for 1961-1990 and 2071$2100^{\mathrm{a}}$

\begin{tabular}{lcc}
\hline Scenario & $\begin{array}{c}\text { Yearly Inflow Toward } \\
\text { La Sotonera Dam }\left(10^{6} \mathrm{~m}^{3}\right)\end{array}$ & $\begin{array}{c}\text { Yearly Delivery Toward } \\
\text { Monegros Channel }\left(10^{6} \mathrm{~m}^{3}\right)\end{array}$ \\
\hline CTRL (1961-1990) & 524.7 & 395.8 \\
CTRL RCAO_E & 531.0 & 396.4 \\
CTRL RCAO_H & 527.6 & 390.9 \\
CTRL HIRHAM_E & 518.0 & 393.3 \\
CTRL HIRHAM_H & 520.7 & 396.0 \\
CTRL HAD_H & 541.1 & 399.6 \\
CTRLARPEGE_H & 522.1 & 397.7 \\
RCAO_E (2071-2100) & $-34.1 \%$ & $-15.7 \%$ \\
RCAO_H(2071-2100) & $-19.4 \%$ & $-3.3 \%$ \\
HIRHAM_E (2071-2100) & $-24.5 \%$ & $-10.0 \%$ \\
HIRHAM_H (2071-2100) & $-21.2 \%$ & $-5.8 \%$ \\
HAD_H (2071-2100) & $-27.6 \%$ & $25(7)$ \\
ARPEGE_H (2071-2100) & $-22.4 \%$ & $-11.7 \%$ \\
\hline
\end{tabular}

${ }^{a} \mathrm{RCM}$ averages are expressed in terms of percentage anomalies with respect to the associated RCM CTRL simulation. The third column shows the number of years in which the incoming fluxes to the reservoir are above the maximum water demanded by agriculture $\left(421.6410^{6} \mathrm{~m}^{3}\right)$ and, within parentheses, the number of years in which the water delivered from the reservoir to the Monegros channel is lower than the maximum water demanded by agriculture even if the incoming flows are above this threshold.
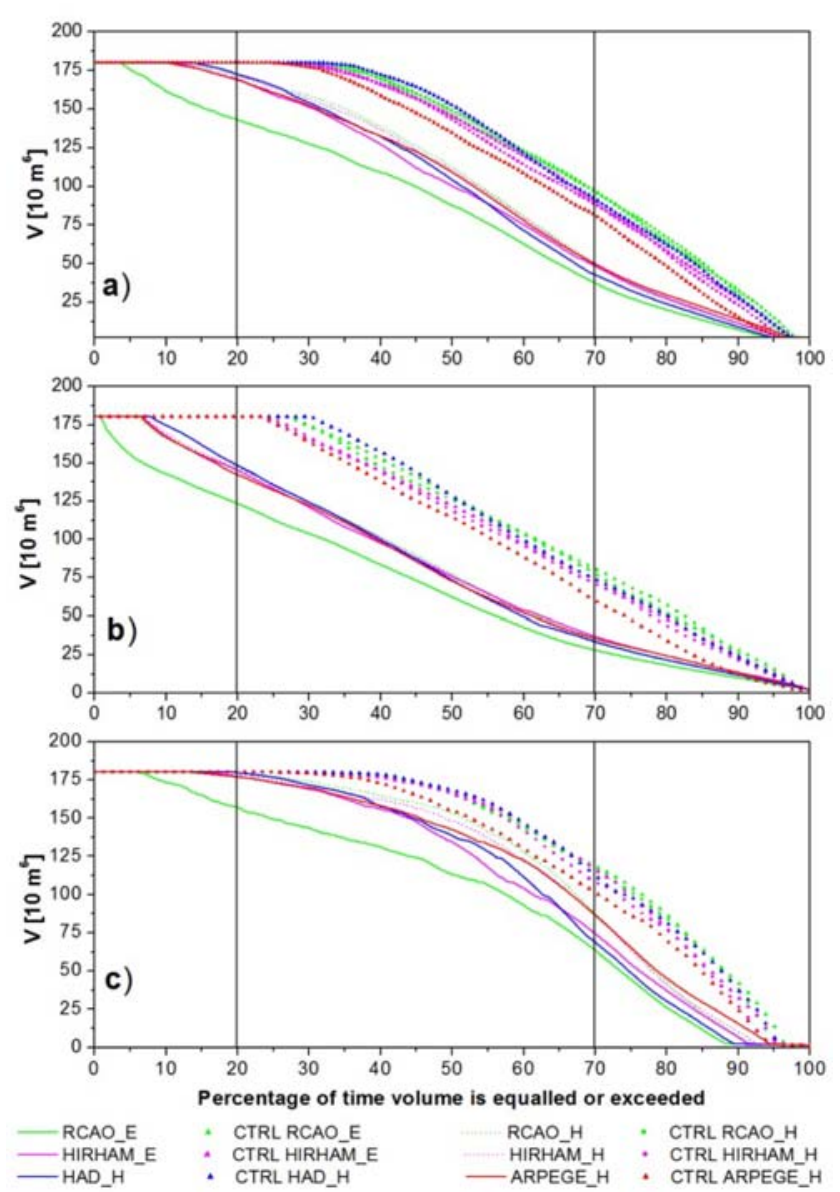

Figure 15. Simulated VDCs calculated at the La Sotonera reservoir during (a) the whole year, (b) the storage period, and (c) the irrigation period for the six different RCM models adopted in the study during the CTRL period 1961-1990 (triangles) and the SCEN time slice 2071-2100 (solid lines). The vertical black lines divide the curves into three portions corresponding to different volume magnitudes: high volumes $(0 \%-20 \%)$, medium volumes $(20 \%-70 \%)$, and low volumes $(70 \%-100 \%)$. their crop choice due to limited water availability. Figure $15 \mathrm{c}$ also shows that uncertainty in impact associated with the choice of RCM increases when moving from high to low volumes, as indicated by the increase in spread of the VDCs. In general, this is wider during the irrigation period than during the storage period (see Figure 15b). This is due to the effects of management rules adopted for the Ardisa reservoir which strictly controls the water fluxes entering the Canal de Gállego channel, rather than to specific seasonal patterns of the meteorological variables projected by the different RCMs.

\section{Conclusions and Discussion}

[51] In this paper, the projected impacts of an ensemble of future climate experiments on streamflow and water resources in the Gállego catchment (Spain) have been assessed. The hydrological model was calibrated with streamflow data for 2000-2005, and the whole modeling framework, i.e., the combination of bias correction of climatic forcing and hydrological modeling, was verified as providing a good reproduction of the streamflow statistics during the control period, 1961-1990. This indicated that the use of bias correction on the mean was justifiable in this instance although for other aspects of the basin hydrology, i.e., reproduction of extreme events, more sophisticated bias correction or downscaling methods would be required. Climate change impacts were then evaluated by comparing streamflow for the 2071-2100 time slice with simulated streamflow for the control period, 1961-1990.

[52] It has been demonstrated that climate change is likely to have substantial effects on the hydrological cycle and water resources in the Gállego catchment. All climate change scenarios in the ensemble project a significant reduction of mean daily streamflow for 2071-2100 with respect to 1961-1990, which reflects the changes in daily precipitation and mean temperature projected by the RCMs. Larger changes are projected in the southern part of the basin where RCMs project the largest decreases in precipitation and increases in temperature. The immediate consequence of these changes is a projected reduction in the amount of water available for irrigation in the La Violada 
and Monegros districts. Inflow to the La Sotonera reservoir is projected to decrease in 2071-2100 and, consequently, the stored volume through the year shows substantially lower storage levels.

[53] Large alterations to streamflow seasonality are also projected for 2071-2100, with the largest changes likely during the irrigation period (April to September) accompanied by small to moderate changes during the storage period (October to March). At La Sotonera reservoir during the storage period, a substantial reduction of stored volume with respect to 1961-1990 may lead to reduced hydropower production. Furthermore, a considerable reduction of low volumes during the irrigation period projected by all the RCMs implies that the agricultural water demand of irrigation districts connected to the La Violada-Monegros system will not be satisfied under the projected climate change scenarios. Alternative solutions may be necessary to adapt agricultural practices, and possibly infrastructure, in order to mitigate the potentially adverse impact of climate change on the water resources of this area.

[54] The effects of climate change on the hydrology and water management in the Gállego are uncertain in relation to the climate model selection. While it is likely that this is derived from a combination of both the GCM providing the boundary conditions and the RCM, the nature of the climate model ensemble does not allow a full exploration of the relative importance of each. Nonetheless, the large differences in the projected impacts on streamflow and water volume stored in La Sotonera reservoir demonstrates that the use of projections from a single climate model ignores a significant source of uncertainty and that the use of climate model ensembles is essential to support decision making on water resources management in this region.

[55] Acknowledgments. We acknowledge financial support by the European Union FP6 Integrated Project Aquaterra (project GOCE 505,428). We also thank the Confederación Hidrográfica del Ebro for data provision. This work was also supported by a NERC postdoctoral Fellowship award to Hayley Fowler (2006-2010) NE/D009588/1.

\section{References}

Alcamo, J., et al. (2007), Europe, in Climate Change 2007: Impacts, Adaptation and Vulnerability. Contribution of Working Group II to the Fourth Assessment Report of the Intergovernmental Panel on Climate Change, edited by M. L. Parry et al., pp. 541-580, Cambridge University Press, Cambridge, U.K.

Allen, R. G., L. S. Pereira, D. Raes, and M. Smith (1998), Crop evapotranspiration. Guidelines for computing crop water requirements, Irrig. Drain. Pap., 56, 1-15.

Beniston, M., et al. (2007), Future extreme events in European climate: An exploration of regional climate model projections, Clim. Change, 81, 71-95.

Beven, K. J., and J. Freer (2001), Equifinality, data assimilation, and uncertainty estimation in mechanistic modelling of complex environmental systems, J. Hydrol., 249, 11-29.

Blenkinsop, S., and H. J. Fowler (2007), Changes in European drought characteristics projected by the PRUDENCE regional climate models, Int. J. Climatol., 27, 1595-1610.

Bovolo C. I., et al. (2011), Climate change, water resources and pollution in the Ebro Basin: Towards an integrated approach, in The Ebro River Basin, Handb. Environ. Chem., edited by D. Barceló and M. Petrovic, vol. 13, pp. 295-329, Springer, New York.

Brunet, M., P. D. Jones, J. Sigró, E. Saladié, E. Aguilar, A. Moberg, P. M. Della-Marta, D. Lister, A. Walther, and D. López (2007), Temporal and spatial temperature variability and change over Spain during 1850-2005, J. Geophys. Res., 112, D12117, doi:10.1029/2006JD008249.
Bürger, C. M., O. Kolditz, H. J. Fowler, and S. Blenkinsop (2007), Learning machines for rainfall-runoff modelling in the Upper Gállego catchment (Spain), Environ. Pollut., 148, 842-854.

Castagna, M., and A. Bellin (2009), A Bayesian approach for inversion of hydraulic tomographic data, Water Resour. Res., 45, W04410, doi:10.1029/ 2008WR007078.

Chow, V. T., D. R. Maidment, and L. W. Mays (1988), Applied Hydrology, McGraw-Hill, New York.

Christensen, J. H., and O. B. Christensen (2007), A summary of the PRUDENCE model projections of changes in European climate by the end of this century, Clim. Change, 81, 7-30, doi:10.1007/s10584-006-9210-7.

Christensen, J. H., et al. (2007a), Regional climate projections, in Climate Change 2007: The Physical Science Basis. Contribution of Working Group I to the Fourth Assessment Report of the Intergovernmental Panel on Climate Change, edited by S. Solomon et al., pp. 849-926, Cambridge University Press, New York.

Christensen, J. H., T. R. Carter, C. M. Rummukainen, and G. Amanatidis (2007b), Evaluating the performance and utility of regional climate models: The PRUDENCE project, Clim. Change. 81, 1-6, doi:10.1007/ s10584-006-9211-6.

Collins, M. (2007), Ensembles and probabilities: a new era in the prediction of climate change, Philos. Trans. R. Soc. A, 365, 1957-1970.

Cudennec, C., C. Leduc, and D. Koutsoyiannis (2007), Dryland hydrology in Mediterranean regions-A review, Hydrol. Sci. J., 52, 1077-1087.

de Castro, M., C. Gallardo, K. Jylhä, and H. Tuomenvirta (2007), The use of a climate-type classification for assessing climate change effects in Europe from an ensemble of nine regional climate models, Clim. Change, 81, 329-341.

Deepashree, R., and P. P. Mujumdar (2010), Reservoir performance under uncertainty in hydrologic impacts of climate change, Adv. Water Resour., 33, 312-326, doi:10.1016/j.advwatres.2009.12.008.

Déqué M., D. P. Rowell, D. Lüthi, F. Giorgi, J. H. Christensen, B. Rockel, D. Jacob, E. Kjellström, M. de Castro, and B. van den Hurk (2007), An intercomparison of regional climate simulations for Europe: Assessing uncertainties in model projections, Clim. Change, 81, 53-70.

Fowler, H. J., and C. G. Kilsby (2007), Using regional climate model data to simulate historical and future river flows in northwest England, Clim. Change, 80, 337-367.

Fowler, H. J., S. Blenkinsop, and C. Tebaldi (2007), Linking climate change modelling to impacts studies: Recent advances in downscaling techniques for hydrological modelling, Int. J. Climatol., 27, 1547-1578.

Gao, X., and F. Giorgi (2008), Increased aridity in the Mediterranean region under greenhouse gas forcing estimated from high resolution simulations with a regional climate model, Global Planet. Change, 62, 195-209.

Gerzabek, M. H., et al. (2007), The integrated project AquaTerra of the EU sixth framework lays foundations for better understanding of riversediment-soil-groundwater systems, J. Environ. Manage., 84, 237-243.

Gonzalez-Hidalgo, J. C., J.-A. Lopez-Bustins, P. îStepánek, J. Martin-Vide, and M. de Luisa (2009), Monthly precipitation trends on the Mediterranean fringe of the Iberian Peninsula during the second-half of the twentieth century (1951-2000), Int. J. Climatol., 29, 1415-1429.

Goodess, C. M., and P. D. Jones (2002), Links between circulation and changes in the characteristics of Iberian rainfall, Int. J. Climatol., 22, 1593-1615.

Gordon, C., C. Cooper, C. A. Senior, H. Banks, J. M. Gregory, T. C. Johns, J. F. B. Mitchell, and R. A. Wood (2000), The simulation of SST, sea ice extents and ocean heat transports in a version of the Hadley Centre coupled model without flux adjustments, Clim. Dyn., 16, 147-168.

Hargreaves, G. H., and Z. A. Samani (1982), Estimating potential evapotranspiration, Technical Note, J. Irrig. Drain. Eng., Am. Soc, Civ. Eng., 108(3), 225-230.

Hewitt, C. D., and D. J. Griggs (2004), Ensembles-based predictions of climate changes and their impacts, Eos, 85, 566.

Jacob, D., et al. (2007), An inter-comparison of regional climate models for Europe: Model performance in present-day climate, Clim. Change, 81(Suppl. 1), 31-52.

Kay, A. L., H. N. Davies, V. A. Bell, and R. G. Jones (2009), Comparison of uncertainty sources for climate change impacts: Flood frequency in England, Clim. Change, 92, 41-63.

Kilsby, C. G., S. S. Tellier, H. J. Fowler, and T. R. Howels (2007), Hydrological impacts of climate change on the Tejo and Guadiana Rivers, Hydrol. Earth Syst. Sci., 11, 1175-1189.

Kirchner, J. W. (2009), Catchment as simple dynamical systems: Catchment characterization, rainfall-runoff modeling, and doing hydrology backward, Water Resour. Res., 45, W02429, doi:10.1029/2008WR006912. 
Kundzewicz, Z. W., et al. (2007), Freshwater resources and their management, in Climate Change 2007: Impacts, Adaptation and Vulnerability. Contribution of Working Group II to the Fourth Assessment Report of the Intergovernmental Panel on Climate Change, edited by M. L. Parry, pp. 173-210, Cambridge University Press, New York.

López-Moreno, J. I., S. Beguería, and J. M. García-Ruiz (2004), The management of a large Mediterranean reservoir: Storage regimens of the Yesa Reservoir, Upper Aragon River Basin, Central Spanish Pyrenees, Environ. Manage., 34, 508-515.

López-Moreno, J. I., S. Goyette, and M. Beniston (2008a), Climate change prediction over complex areas: Spatial variability of uncertainties and predictions over the Pyrenees from a set of regional climate models, Int. J. Climatol., 28, 1535-1550.

López-Moreno, J. I., J. M. García-Ruiz, and M. Beniston (2008b), Environmental change and water management in the Pyrenees. Facts and future perspectives for Mediterranean mountains, Global Planet. Change, 66 , 300-312.

López-Moreno, J. I., S. Goyette, and M. Beniston (2009), Impact of climate change on snowpack in the Pyrenees: Horizontal spatial variability and vertical gradients, J. Hydrol., 374, 384-396.

López-Moreno, J. I., S. M. Vicente-Serrano, M. Angulo-Martínez, S. Beguería, and A. Kenawy (2010a), Trends in daily precipitation on the northeastern Iberian Peninsula, 1955-2006, Int. J. Climatol., 30, 10261041.

López-Moreno, J. I., S. M. Vicente-Serrano, E. Moran-Tejeda, J. Zabalza, J. Lorenzo-Lacruz, and J. M. García-Ruiz (2010b), Impact of climate evolution and land use changes on water yield in the Ebro basin, Hydrol. Earth Syst. Sci. Discuss., 7, 2651-2681.

Majone, B., A. Bertagnoli, and A. Bellin (2010), A non-linear runoff generation model in small Alpine catchments, J. Hydrol., 385, 300-312, doi:10.1016/j.jhydrol.2010.02.033.

Martínez, M. D., C. Serra, A. Burgueño, and X. Lana (2010), Time trends of daily maximum and minimum temperatures in Catalonia (ne Spain) for the period 1975-2004, Int. J. Climatol., 30, 267-290.

Michel, C., V. Andreassian, and C. Perrin (2005), Soil Conservation Service Curve Number method: How to mend a wrong soil moisture accounting procedure?, Water Resour. Res., 41, W02011, doi:10.1029/2004 WR003191.

Milly, P. C. D., K. A. Dunne, and A. V. Vecchia (2005), Global pattern of trends in streamflow and water availability in a changing climate, Nature, 438(7066), 347-350, doi:10.1038/nature04312.

Milly, P. C. D., J. Betancourt, M. Falkenmark, R. M. Hirsch, Z. W. Kundzewicz, D. P. Lettenmaier, and R. J. Stouffer (2008), Stationarity is dead: Whither water management?, Science, 319, 573-574.

Murphy, J. M., B. B. B. Booth, M. Collins, G. R. Harris, D. Sexton, and M. Webb (2007), A methodology for probabilistic predictions of regional climate change from perturbed physics ensembles, Philos. Trans. R. Soc. A, 365, 1993-2028, doi:10.1098/rsta.2007.2077.

Nakícenovíc, N., et al. (2000), Emissions scenarios, in Special report on emissions scenarios: A special report of working group III of the Intergovernmental Panel on Climate Change, edited by N. Nakícenovíc and R. Swart, 600 pp., Cambridge University Press, New York.

Nash, J. E., and J. V. Sutcliffe (1970), River flow forecasting through conceptual models 1. A discussion of principles, J. Hydrol., 10, 282-290.

New, M., A. Lopez, S. Dessai, and R. Wilby (2007), Challenges in using probabilistic climate change information for impact assessments: An example from the water sector, Philos. Trans. R. Soc. A, 365, 2117-2131, doi: $10.1098 /$ rsta.2007.2080.

Pope, V. D., M. L. Gallani, P. R. Rowntree, and R. A. Stratton (2000), The impact of new physical parameterizations in the Hadley Centre climate model: HadAM3, Clim. Dyn., 16, 123-146.
Prudhomme, C., and H. Davies (2009), Assessing uncertainties in climate change impact analyses on the river flow regimes in the UK. Part 1: Baseline climate, Clim. Change, 93, 177-195.

Rinaldo, A., G. Botter, E. Bertuzzo, A. Uccelli, T. Settin, and M. Marani (2005), Transport at basin scales: 1. Theoretical framework, Hydrol. Earth Syst. Sci., 10, 19-29.

Roeckner, E., et al. (1996), The atmospheric general circulation model ECHAM-4: Model description and simulation of present-day climate, Rep. 218, 90 pp., Max-Planck Inst. for Meteorol., Hamburg, Germany.

Robinson, J., and Y. Rahmat-Samii (2004), Particle swarm optimization in electromagnetics, IEEE Trans. Antennas Propag., 52(2), 397-407.

Rodrigo, F. S. (2010), Changes in the probability of extreme daily precipitation observed from 1951 to 2002 in the Iberian Peninsula, Int. J. Climatol., 30, 1512-1525.

Rodrigo, F. S., and R. M. Trigo (2007), Trends in daily rainfall in the Iberian Peninsula from 1951 to 2002, Int. J. Climatol., 27, 513-529.

Rodríguez-Iturbe, I., and A. Rinaldo (1997), Fractal River Basins-Chance and Self-Organization, Cambridge University Press, New York.

Rodríguez-Iturbe, I., and J. Valdes (1979), The geomorphological structure of hydrogeological response, Water Resour. Res., 15, 1409-1420.

Seibert, J. (2003), Reliability of model predictions outside calibration conditions, Nord. Hydrol., 34, 477-492.

Tanaka, S. K., T. Zhu, J. R. Lund, R. E. Howitt, M. W. Jenkins, M. A. Pulido, M. Tauber, R. S. Ritzema, and I. C. Ferreira (2006), Climate warming and water management adaptation for California, Clim. Change, 76, 361-387, doi:10.1007/s10584-006-9079-5.

Tebaldi, C., and R. Knutti (2007), The use of the multi-model ensemble in probabilistic climate projections, Philos. Trans. R. Soc. A, 365, 2053-2075.

U.S. Soil Conservation Service (1964), Hydrology, Section 4, SCS National Engineering Handbook, Washington D.C.

van der Linden, P., and J. F. B. Mitchell (Eds) (2009), ENSEMBLES: Climate change and its impacts: Summary of research and results from the ENSEMBLES project, 160 pp., Met Off. Hadley Cent., U.K.

Vicuna, S., J. A. Dracup, J. R. Lund, L. L. Dale, and E. P. Maurer (2010), Basin scale water system operations with uncertain future climate conditions: Methodology and case studies, Water Resour. Res., 46, W04505, doi:10.1029/2009WR007838.

Wilby, R. L., and S. Dessai (2010), Robust adaptation to climate change, Weather, 65, 180-185.

Wilby, R. L., and T. M. L. Wigley (1997), Downscaling general circulation model output: A review of methods and limitations, Prog. Phys. Geogr., $21,530-548$

Yao, H., and A. Georgakakos (2001), Assessment of Folsom Lake response to historical and potential future climate scenarios: 2 . Reservoir management, J. Hydrol., 249, 176-196, doi:10.1016/S0022-1694(01)00418-8.

Yapo, P. O., H. V. Gupta, and S. Sorooshian (1996), Automatic calibration of conceptual rainfall-runoff models: Sensitivity to calibration data, $J$. Hydrol., 181, 23-48.

Yilmaz, K. K., H. V. Gupta, and T. Wagener (2008), A process-based diagnostic approach to model evaluation: Application to the NWS distributed hydrologic model, Water Resour. Res. 44(9), W09417, doi:10.1029/ 2007WR006716.

A. Bellin and B. Majone, Department of Civil and Environmental Engineering, University of Trento, Via Mesiano 77, I-38123 Trento, Italy. (bruno.majone@ing.unitn.it)

S. Blenkinsop, C. I. Bovolo, and H. J. Fowler, Water Resource Systems Research Laboratory, School of Civil Engineering and Geosciences, Newcastle University, Claremont Rd., Newcastle upon Tyne, NR1 7RU, England, UK. 